UNIVERSIDADE DE SÃO PAULO

HOSPITAL DE REABILITAÇÃO DE ANOMALIAS CRANIOFACIAIS

\title{
PERFIL DAS HABILIDADES DE LINGUAGEM DE INDIVÍDUOS COM FISSURA LABIOPALATINA
}

FABIANA CARLA MARCELINO

Tese apresentada ao Hospital de Reabilitação de Anomalias Craniofaciais da Universidade de São Paulo para obtenção do título de DOUTOR em Ciências da Reabilitação, área de concentração: Fissuras Orofaciais e Anomalias Relacionadas.

\section{BAURU}


UNIVERSIDADE DE SÃO PAULO

HOSPITAL DE REABILITAÇÃO DE ANOMALIAS CRANIOFACIAIS

\section{PERFIL DAS HABILIDADES DE LINGUAGEM DE INDIVÍDUOS COM}

\section{FISSURA LABIOPALATINA}

FABIANA CARLA MARCELINO

Orientador: Profa. Dra. Luciana Paula Maximino

Tese apresentada ao Hospital de Reabilitação de Anomalias Craniofaciais da Universidade de São Paulo para obtenção do título de DOUTOR em Ciências da Reabilitação, área de concentração: Fissuras Orofaciais e Anomalias Relacionadas. 


\section{Universidade de São Paulo}

\section{Hospital de Reabilitação de Anomalias Craniofaciais}

Rua Sílvio Marchione, 3-20

Caixa Postal: 1501

17012-900 Bauru/SP - Brasil

(14) $3235-8000$

Profa. Dra. Suely Vilela - Reitora da USP

Prof. Dr. José Alberto de Souza Freitas - Superintendente do HRAC-USP

Autorizo, exclusivamente para fins acadêmicos e científicos, a reprodução total ou parcial deste trabalho.

Fabiana Carla Marcelino

Bauru, 06 de novembro de 2009.

\footnotetext{
Marcelino, Fabiana Carla

M331p Perfil das habilidades de linguagem de indivíduos com fissura labiopalatina./ Fabiana Carla Marcelino. Bauru, 2009. 83f.; il.; $30 \mathrm{~cm}$.

Tese (Doutorado em Ciências da Reabilitação - Área de Concentração: Fissuras Orofaciais e Anomalias Relacionadas) - HRAC-USP

Orientador: Profa. Dra. Luciana Paula Maximino

Descritores: 1. Fissura palatina 2. Fenda labial 3. Comunicação 4. Transtornos da Linguagem 5. Percepção Auditiva
} 
FOLHA DE APROVAÇÃO

Tese apresentada e defendida por

FABIANA CARLA MARCELINO

e aprovada pela Comissão Julgadora em l

Prof.(a) Dr.(a):

Instituição:

Prof.(a) Dr.(a):

Instituição:

Prof.(a) Dr.(a):

Instituição:

Prof.(a) Dr.(a):

Instituição:

Prof.(a) Dr.(a):

Instituição:

Profa. Dra. Inge Elly Kiemle Trindade

Presidente da Comissão de Pós-Graduação do HRAC-USP

Data de depósito da tese junto à CPG: / / 


\section{FABIANA CARLA MARCELINO}

05 de outubro de $1976 \quad$ Nascimento.

Bauru - SP

1997-2000

Graduação em Fonoaudiologia na Faculdade de Odontologia de Bauru - USP.

2000-2000

Iniciação Científica no Departamento de Patologia da FOB-USP. Bolsa: Fapesp.

2001-2002

Aprimoramento em Fonoaudiologia aplicada à Neurologia Infantil no Hospital das Clínicas - UNICAMP. Bolsa: Fundap.

2002-2004

Curso de Pós-Graduação em Ciências da Reabilitação, área: Distúrbios da Comunicação Humana, em nível de mestrado, no HRAC-USP. Bolsa: Capes.

2005-atual

Docente e supervisora do Curso de Fonoaudiologia da Fundação Educacional de Fernandópolis.

2006-2009

Curso de Pós-Graduação em Ciências da Reabilitação, área: Fissuras Orofaciais e Anomalias Relacionadas, em nível de doutorado, no HRAC-USP.

2007-atual

Docente do Curso de Pedagogia do Instituto de Ensino Superior de Bauru - IESB.

2009-atual

Coordenadora do Aprimoramento em Diagnóstico e Intervenção Fonoaudiológica, Fundação Educacional de Fernandópolis. 
Dedico este trabalho

À Profa Dra Luciana Paula Maximino por sua orientação e amizade desde o início de minha formação. Agradeço sua disponibilidade e competência na orientação deste trabalho. 


\section{Agradecimentos}

A todos que colaboraram para a realização desta pesquisa.

Em especial: Dra Jeniffer C. R. Dutka, Dra Mariza Ribeiro Feniman e Dra Dagma V. M. Abramides pelo auxílio inestimável neste trabalho.

À Dra Maria Inês Pegoraro-Krook por permitir a realização desta pesquisa; à Andréa Evangelista S. Correia por sua ajuda incomensurável na seleção das crianças; às Fgas Camila Zotelli Monteiro, Renata Camargo, Ariane Rissato pela realização das avaliações audiológicas e do processamento auditivo; à Fga Melina Evangelista Whitaker pela parceria em muitos momentos.

À Dra Inge E. K. Trindade, Presidente da Comissão de Pós-Graduação do HRAC-USP.

Aos funcionários da Sessão de Pós-Graduação: Andréia, Maria José e Rogério.

Aos pacientes e seus familiares.

Aos meus pais, familiares e amigos pelo amor e amizade. Por me apoiarem em cada momento.

Ao marido e companheiro David Lucas Desidério, por me estimular a ampliar o olhar, compreender o que não é visível. 


\section{SUMÁRIO}

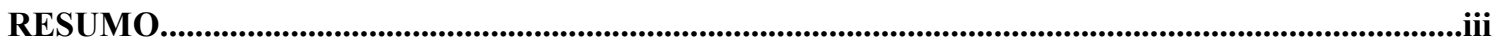

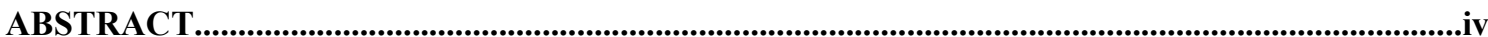

1. INTRODUÇÃO E REVISÃO DE LITERATURA.......................................................................................

2. OBJETIVO. .................................................................................................................................................

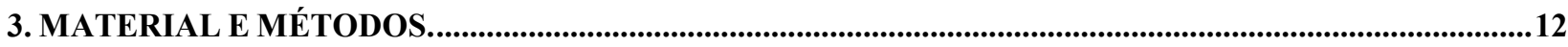

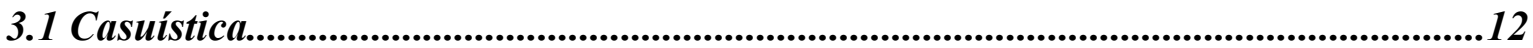

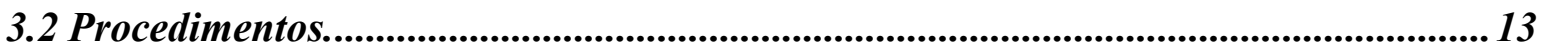

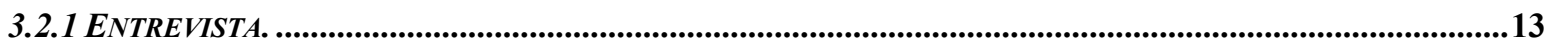

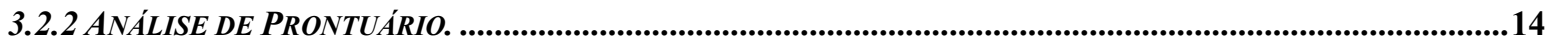

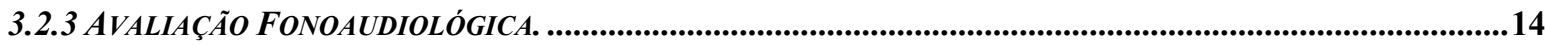

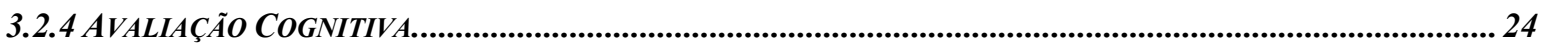

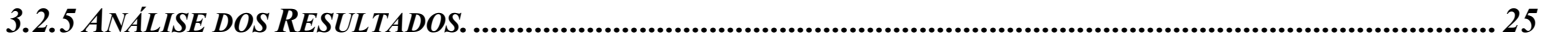

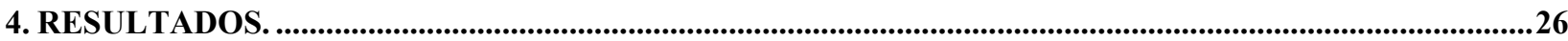

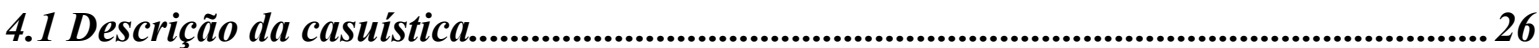

4.2 Achados da entrevista e observação clínica.......................................................... 26

4.3 Achados do prontuário ..............................................................................................................227

4.4 Avaliação Complementar. .................................................................................................. 29

a) Teste Illinois de Habilidades Psicolingüísticas - ITPA................................................29

b) Teste de Vocabulário por Imagens - Peabody (TVIP) .................................................... 31

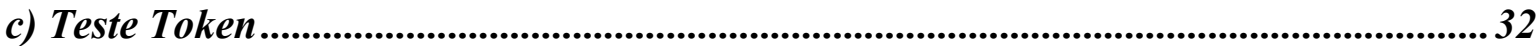

d) Perfil de Habilidades Fonológicas (PHF)...................................................................33

e) Teste do Desempenho Escolar (TDE)................................................................ 34

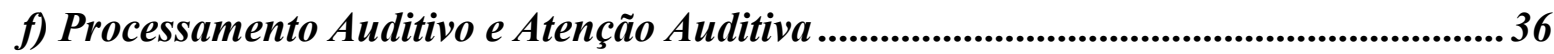

4.5 Avaliação Cognitiva............................................................................................................ 38

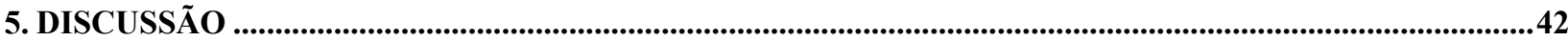

6. CONCLUSÃO

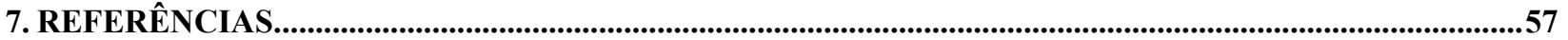

8. BIBLIOGRAFIA CONSULTADA....................................................................................................................71

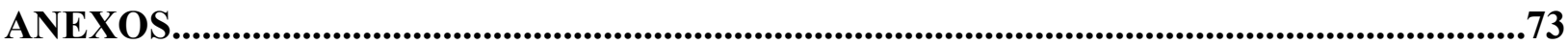


Marcelino FC. Perfil das habilidades de linguagem de indivíduos com fissura labiopalatina [tese]. Bauru: Hospital de Reabilitação de Anomalias Craniofaciais, Universidade de São Paulo; 2009.

Objetivo: caracterizar o perfil das habilidades de linguagem (oral e escrita) e habilidades auditivas e visuais de indivíduos com fissura labiopalatina (FLP).

Modelo/ Participantes: estudo prospectivo em 24 indivíduos com FLP, entre 7 e 9 anos de idade, de ambos os sexos, matriculados no Hospital de Reabilitação de Anomalias Craniofaciais,Universidade de São Paulo (HRAC-USP).

Local de execução: Setor de Genética Clínica do HRAC-USP.

Variáveis: habilidades semântica, sintática, fonológica e pragmática da linguagem oral, por meio de observação clínica; memória auditiva e visual, associação auditiva e visual, closura gramatical e visual, recepção da linguagem, vocabulário receptivo, processamento fonológico, escrita, aritmética, leitura, processamento e atenção auditiva, por meio de provas e testes.

Resultados: Na observação clínica dez indivíduos apresentaram normalidade na expressão de todos os componentes da linguagem oral, tanto do ponto de vista receptivo quanto expressivo. Foi observado maior déficit na habilidade de associação auditiva e visual e closura visual; vocabulário receptivo adequado na maioria da amostra (84\%); compreensão oral rebaixada em $54 \%$ dos indivíduos; $38 \%$ da amostra apresentaram dificuldade nas habilidades fonológicas e $50 \%$ no desempenho escolar. No processamento e atenção auditiva houve dificuldade em quase toda a amostra (96\%). A capacidade cognitiva estava dentro da normalidade em todos os indivíduos analisados.

Conclusão: $\mathrm{O}$ desempenho das habilidades de linguagem estava aquém do esperado para a idade na maioria dos indivíduos com FLP avaliados. As habilidades mais prejudicadas foram escrita, associação auditiva, linguagem receptiva, associação visual, leitura e aritmética. As habilidades do processamento e atenção auditiva analisadas estavam defasadas em quase todos os indivíduos avaliados.

Descritores: Fissura palatina, Fenda labial, Comunicação, Transtornos da Linguagem, Percepção Auditiva. 
Marcelino FC. Language abilities profile of individuals with cleft lip and palate [thesis]. Bauru: Hospital de Reabilitação de Anomalias Craniofaciais, Universidade de São Paulo; 2009.

Objectives: To characterize the language abilities profile (oral and written) and auditory and visual abilities of individuals with cleft lip and palate (CLP).

Model/ Participants: prospective study in 24 individuals with CLP, from 7 to 9 years old, both mail and female, enrolled at Hospital de Reabilitação de Anomalias Craniofaciais, Universidade de São Paulo (HRAC-USP).

Execution Site: HRAC-USP Sector of Clinical Genetics.

Variables: Semantic abilities, syntax, phonological and pragmatic aspects of oral language, by means of clinical observation; auditory and visual memory, auditory and visual association, Grammar and visual closure, language reception, receptive vocabulary, phonological processing, writing, Arithmetic, reading, auditory attention and processing, by means of proofs and tests.

Results: In the clinical observation, tem individuals presented normality in the expression of all the oral language aspects (components), both in the receptive and the expressive point of view. It was observed a higher deficit in the auditory and visual association and visual closure abilities; adequate receptive vocabulary in the majority of the sample (84\%); lowered oral comprehension in $54 \%$ of the individuals; $38 \%$ of the sample presented difficulties in phonological abilities and $50 \%$ in school performance. In the auditory attention and processing it was found difficulties in almost all the sample (96\%). The cognitive capacity was inside normality in all the analyzed individuals.

Conclusions: The language abilities' performance was beneath the expected for the age in the majority of the evaluated individuals with CLP. The most prejudiced abilities were: written, auditory association, receptive language, visual association, reading and Arithmetic. The evaluated auditory attention and processing abilities were lowered in almost all the assessed individuals.

Key Words: Cleft Palate, Cleft Lip, Communication, Language Disorders, Auditory Perception. 


\section{INTRODUÇÃO E REVISÃO DE LITERATURA.}

Ao estudar a linguagem do ser humano é necessário pensá-lo como indivíduo integral. A criança não desenvolve a linguagem isoladamente de outras dimensões pessoais e sociais, mas conjuntamente com a compreensão do mundo que a rodeia. Durante a primeira infância o esforço do indivíduo em organizar as informações que recebe a cada momento é extremamente complexo (Marcelino e Hamer 2009). Nesta fase surge a linguagem, habilidade pela qual o ser humano se comunica, se expressa, transforma a si e o mundo, cria relações, organiza-se e desenvolve-se em plenitude.

A Fonoaudiologia é a ciência que estuda a comunicação, sua aquisição, desenvolvimento, distúrbios, prevenção, aprimoramento, habilitação e reabilitação individual ou em grupo. A comunicação permite ao indivíduo relacionar-se, transformar a si e o meio, aprimorando seu pensamento, suas relações, enfim, o universo. Os distúrbios da comunicação humana podem ter como causa alterações de base congênita, dentre as quais as fissuras labiopalatinas (FLP).

A população com FLP oferece um campo de estudos dos distúrbios da comunicação, os quais são comuns nessa população em decorrência das alterações estruturais e funcionais inerentes à fissura. As alterações estruturais, nesta população, comprometem tanto a estética quanto a funcionalidade do sistema estomatognático para o desempenho das funções orais. Desta forma, interferem no processo de comunicação, levando a prejuízos na interação social, devido ao grande comprometimento da fala e da estética facial, podendo interferir na formação da autoimagem do indivíduo (Nguyen e Sullivan 1993, Minervino-Pereira 2000). Quanto ao processo da comunicação, esta malformação traz conseqüências para a fala, visto que acomete estruturas importantes que respondem pela produção da mesma, proporcionando alterações específicas 
relacionadas à disfunção velofaríngea, bem como à deformidade dentofacial, e também funcionamento da orelha média (Genaro et al 2004, Pegoraro-Krook et al 2004).

Em particular com relação às habilidades lingüísticas, é comum encontrar autores que sugerem que a criança com FLP isolada (sem estar acompanhada de outras condições como síndromes, por exemplo) tende a desenvolver linguagem apresentando alterações nas habilidades lingüísticas em uma mesma proporção que as crianças sem FLP (ou sem outra condição aparente, denominadas como crianças "normais"), com exceção de atraso de linguagem que tende a ser superado ao redor dos 4 anos (Golding-Kushner 2001, Bzoch, 2004). Um olhar mais recente às habilidades comunicativas das crianças com FLP, no entanto, tem apontado para diferenças significativas no desenvolvimento das habilidades da linguagem, diferenças estas diretamente relacionadas ao desempenho escolar (Broder et al 1998, Richman et al 2005, Goldsberry et al 2006). Com um olhar particular às habilidades lingüísticas de crianças com FLP, foi delineado este trabalho.

\section{Fissura Labiopalatina: Aspectos Gerais}

As FLP são as anomalias congênitas mais comuns que comprometem a face dos seres humanos (Tolarová e Cervenka 1998), com incidência de 1 em cada 1000 recém-nascidos. Os fatores causais das FLP são amplamente estudados e descritos como tendo etiologia multifatorial na qual o componente genético associado a fatores ambientais tem sido referido (Murray 1995). As fissuras palatinas compreendem, em geral, uma malformação isolada, isto é, não sindrômica, porém muitas vezes associada a outras malformações. Felix et al (2002) avaliaram, do ponto de vista genético clínico, 282 pacientes com fissura, sendo 142 do sexo masculino e 140 do sexo feminino, com idades de 1 mês a 52 anos. Concluíram com o estudo que a maioria (77,3\%) eram casos isolados e 22,7\% apresentavam outras malformações associadas. As FLP isoladas, em 
particular, foram o objeto de interesse neste estudo.

Dentre a diversidade de sistemas de classificação das FLP, o adotado pelo Hospital de Reabilitação de Anomalias Craniofaciais (HRAC) é o proposto por Spina et al (1972), modificado por Silva Filho et al (1992). Esta classificação toma como ponto de referência anatômica o forame incisivo, vestígio pós-natal da junção do palato primário com o palato secundário. A mesma é subdivida em pré-forame incisivo; transforame incisivo, pós-forame incisivo e fissuras raras da face, sendo ainda que a fissura pode ser completa ou incompleta. Neste estudo o enfoque foi na FLP transforame incisivo.

\section{Fissura Labiopalatina: Alterações da Comunicação}

Dentre os tipos de fissura encontrados, aqueles que envolvem o palato afetam mais a fala devido ao acometimento da função velofaríngea, responsável por manter a pressão aérea intraoral e direcionar o fluxo aéreo para a cavidade oral durante a produção de fonemas orais, bem como equilibrar a ressonância oronasal (Bzoch 2004, Nguyen e Sullivan 1993, Trindade e Trindade Júnior 1996, Altmann et al 1997 e Igawa 1998). Na produção de fala normal, os processos de fonação, ressonância e articulação estão intimamente relacionados. A ação do esfíncter velofaríngeo garante que esses processos sejam produzidos com eficiência. Se o

esfíncter velofaríngeo for disfuncional, podem existir conseqüências adversas para a fala (Stengelhofen 1989, McWilliams et al 1990, Wyatt et al 1996).

Melgaço et al (2002) observaram a necessidade de prevenção, diagnóstico e tratamento das anomalias dentárias e maxilofacias em indivíduos com FLP e apontaram dificuldades alimentares e alterações na comunicação, como atraso da fala e da linguagem, distúrbios articulatórios, vocais e auditivos. O distúrbio da audição apresenta ocorrência significativa nesta 
população, pois as alterações anatomofuncionais, em especial a disfunção tubária e a presença de refluxo nasal, tornam o indivíduo propenso a desenvolver quadros de otite de repetição e perda auditiva condutiva (Broen et al 1996, Pegoraro-Krook et al 2004).

Moore et al (1986) afirmou que mesmo períodos curtos de perda condutiva, tanto em adultos quanto em crianças podem resultar em sérias conseqüências para o processamento auditivo. De acordo com o Grupo de Distúrbios do Processamento Auditivo da American Speech-Language-Hearing Association - ASHA (2005) as alterações do processamento auditivo podem coexistir com outros distúrbios, tais como os de linguagem e os de aprendizagem. Tallal e Stark (1981), Benasich et al (2002), McArthur e Bishop (2004a, 2004b), Wible et al (2005), Sharma et al (2009) verificaram coexistência de alterações de linguagem e do processamento auditivo em crianças sem FLP. Entretanto, Bishop et al (1999), Rosen (1999) não encontraram dificuldades específicas nas tarefas do processamento auditivo em crianças com distúrbio específico de linguagem.

A freqüência de otite média com efusão em indivíduos com FLP é alta e pode levar a uma perda auditiva periférica, podendo esta ser um indicador de risco para o desenvolvimento do processamento auditivo, da linguagem, da fala e da aprendizagem. No entanto, de acordo com Pegoraro-Krook et al (2004) o tubo de ventilação não é considerado um tratamento adequado para otite média crônica, mas quando a otite permanece traz seqüelas para o desenvolvimento de linguagem e o potencial cognitivo, devido à privação sensorial presente nestes casos. Tais seqüelas cognitivas e lingüísticas podem ser minimizadas ou prevenidas por meio da identificação precoce e da reabilitação.

A perda auditiva associada à otite média é um dos maiores obstáculos ao desenvolvimento normal de linguagem (Feagans et al 1987, Friel-Patti e Finitzo 1990, Roberts et al 1995, Jocelyn et al 1996, Shriberg et al 2000). Os pais, portanto, devem ser muito bem orientados de quanto 
isso pode prejudicar o desenvolvimento da linguagem oral, sendo a audição monitorada periodicamente e a otite média tratada de acordo com cada caso (Dixon-Wood 2004). O fonoaudiólogo, como membro da equipe interdisciplinar, além de ter conhecimento das causas determinantes das complicações otológicas presentes, deve avaliar todo o sistema vestibulococlear e não somente um segmento periférico, contribuindo para o processo de prevenção, terapia e estabelecimento de condutas adequadas (Pegoraro-Krook et al 2004).

Qualquer transtorno anatômico ou fisiológico nos processos de fonação, ressonância e articulação pode trazer conseqüências lingüísticas para o indivíduo. Os problemas de articulação e ressonância, em particular, podem resultar em falhas na sinalização de diferenças significantes entre os sons da fala, resultando em transtornos fonéticos e fonológicos. Isso por sua vez, leva a falhas de comunicação que podem resultar em defeitos de comunicação e incapacidade de gerar reforço recíproco e ampliar as respostas do ouvinte. Para a criança nos estágios iniciais do desenvolvimento da linguagem, esse ciclo de falhas pode ser bastante prejudicial, não somente para o desenvolvimento da fala, mas também para o desenvolvimento do léxico e da gramática (Grunwell e Sell 2005). Konst et al (2003) não observaram alterações de linguagem em crianças com FLP e alterações ortodônticas/ortopédicas.

É evidente o problema articulatório conseqüente à FLP (Snyder e Scherer 2004), comprometendo a inteligibilidade da fala, bem como a inter-relação do sujeito com o meio. Entretanto, também há evidências de riscos para o desenvolvimento da linguagem em pacientes com tais malformações (McWilliams et al 1990, Richman e Eliason 1995, Scherer e D’Antonio1995, Jocelyn et al 1996, Schönweiler et al 1999). Outros autores verificaram atraso de linguagem em crianças com fissura na faixa etária de até 3 anos de idade (Pamplona et al 2000a, Melgaço et al 2002, Morris e Ozanne 2003, Sharp et al 2003).

Richman e Eliason (1984) estudaram crianças com fissura de palato em idade escolar 
entre 8 e 13 anos e observaram baixo desempenho em associação de linguagem, memória auditiva de curto prazo e compreensão de leitura quando comparados à crianças com FLP. Eliason e Richman (1990) constataram atraso de linguagem em crianças com FLP entre 5 e 6 anos, observando déficit na habilidade de mediação verbal quando comparadas a crianças sem FLP. Neiman e Savage (1997) não verificaram risco ou atraso no desenvolvimento da linguagem expressiva em crianças com fissura de palato até os 36 meses. Chapman et al (1998) não encontraram diferença significativa de linguagem entre crianças sem e com FLP unilateral, mas ao analisar individualmente cada caso verificaram que 50\% das crianças com FLP exibiram pouca participação conversacional. Broder et al (1998) ressaltaram que crianças com FLP em idade escolar (6 a 18 anos) apresentavam alta incidência de dificuldades de aprendizagem, desempenho abaixo da média e alta freqüência de repetência.

Pamplona et al (2000a) avaliaram dois grupos de crianças operadas de fissura de palato, sendo um com articulação compensatória e outro sem, para verificar a relação entre articulação compensatória e o desenvolvimento da linguagem. Foi constatado que os pacientes com articulação compensatória apresentavam alta freqüência de atraso da linguagem quando comparados com pacientes sem articulação compensatória. Todos os pacientes com articulação compensatória exibiram um nível inferior de organização lingüística em três contextos avaliativos: situacional, discursivo e semântico. Sharp et al (2003) discutiram as alterações da produção da fala, linguagem e de compreensão presentes em crianças com fissura. Concluíram que tais crianças têm maior predisposição de apresentar atraso na aquisição das primeiras palavras, na produção de sentenças curtas, dificuldade na recuperação de palavras, na compreensão da linguagem e deficiência no raciocínio, quando comparadas com seus pares com desenvolvimento normal.

Morris e Ozanne (2003) avaliaram vinte crianças com fissura de palato aos dois e três 
anos de idade, para relacionar as habilidades fonológicas, fonéticas e de linguagem com a fissura de palato, por meio de avaliações padronizadas e discurso espontâneo. Nove crianças apresentaram atraso de linguagem expressiva, e onze mostraram desenvolvimento normal da linguagem. Foram discutidas três etiologias propostas na literatura: deficiência anatômica, atraso da maturidade cognitivo-lingüística e desordens fonológicas. O grupo com atraso da linguagem expressiva continuou apresentando dificuldades aos três anos e desordens do desenvolvimento da fala quando comparado ao grupo não atrasado.

\section{Fissura labiopalatina: Tratamentos Preconizados}

$\mathrm{Na}$ maioria dos centros ao redor do mundo a fissura transforame incisivo completa, isolada, é tratada cirurgicamente. Muitos centros de reabilitação advogam que o fechamento do palato deva ser realizado cirurgicamente entre 9 e 12 meses de idade, entretanto, não existe um consenso na literatura (Schönweiler et al 1999). No HRAC em particular o reparo primário do lábio e pré-maxila (queiloplastia primária) é proposto entre 3 e 6 meses de idade enquanto o reparo do palato (palatoplastia primária) é proposto entre 12 e 18 meses de idade. Hall e GoldingKushner (1989) afirmaram que cerca de $80 \%$ das crianças que nascem com FLP e são submetidas à cirurgia antes de 18 meses de idade desenvolvem fala normal.

Segundo Gomes e Mélega (1997) faz-se necessário intervir o mais precocemente possível, a fim de eliminar ou amenizar as seqüelas negativas para a comunicação do indivíduo com FLP, esta intervenção pode ser cirúrgica e/ou reabilitadora dos problemas de comunicação decorrentes desta malformação. Após a reconstrução cirúrgica do palato a criança terá estrutura necessária para iniciar a produção de sons orais. Muitos pais relatam aumento da emissão oral e das habilidades de linguagem expressiva após a cirurgia de palato, o que pode ser devido à estruturação do palato e/ou à melhora da audição pela equalização de pressão aérea na orelha 
média. Embora a literatura refira que há melhora do funcionamento do músculo tensor do véu após o fechamento do palato, os episódios de otites podem continuar constantes (Nunn et al 1995, Pegoraro-Krook et al 2004).

Bzoch et al (1984), O’Gara e Logemann (1988), Philips (1990), Golding-Kushner (2001), Dixon-Wood (2004) propõem como prevenção o aconselhamento e treinamento precoce e domiciliar aos pais, cujo foco deve ser a aquisição e desenvolvimento normal da linguagem e fala, onde entendam que as habilidades de linguagem receptiva e expressiva estão relacionadas à função simbólica da comunicação e que a fala refere-se ao aspecto motor (articulação, fluência e voz), ainda quais as habilidades devem ser estimuladas em cada faixa etária, além de atividades para serem realizadas em casa.

Philips (1990), O’Gara e Logemann (1988) propuseram programas de intervenção precoce, visando a estimulação de fala e de linguagem entre o nascimento e os 3 anos de idade para crianças com FLP e outras síndromes associadas a esta malformação. Para a faixa etária dos 3 aos 12 meses, os autores afirmaram que o enfoque principal deve estar voltado à orientação aos pais quanto aos aspectos relacionados ao desenvolvimento de fala, de linguagem, à alimentação e à audição. Dos 12 aos 30 meses, o fonoaudiólogo deverá desenvolver um trabalho de monitorização dos padrões de fala e de linguagem, visando o apoio e a promoção do desenvolvimento fonológico e lingüístico destas crianças. A partir dos 30 meses, as autoras preconizam a intervenção direta por meio de fonoterapia.

Segundo Musolino e Rodrigues (1995) e Schönweiler et al (1998) cuidados efetivos para com uma criança comprometida dependem da experiência de muitos especialistas competentes realizando uma abordagem interdisciplinar, o que requer interação do grupo trazendo experiência útil na solução de um problema médico. O direcionamento interdisciplinar é baseado em muitos conceitos inter-relacionados. Respeitar a experiência do outro membro é de suma importância, 
além de uma base de conhecimentos compartilhados e associados à solução criativa de problemas para pesquisas frutíferas. Sharp et al (2003) ressaltam o trabalho da equipe interdisciplinar como essencial para a realização de diagnóstico e planejamento do tratamento apropriado.

Existem relatos na literatura de que crianças nascidas com fissura de palato apresentam atraso no desenvolvimento da linguagem, conforme já citado anteriormente. A alta prevalência de otite, hospitalizações e outros fatores comumente encontrados nesta população podem aumentar o risco para que este atraso ocorra. Desta forma, recomenda-se que todas as crianças com FLP sejam consideradas de risco para alterações de comunicação. Crianças com fissura somente de palato deveriam ser consideradas de maior risco para alteração da linguagem, e a suspeita da presença de síndromes, deveria ser muito bem investigada. Entretanto, para as crianças com FLP sem suspeita de síndromes, devem-se ter as mesmas expectativas quanto ao desenvolvimento de linguagem que se tem para as demais crianças nascidas sem fissura (Golding-Kushner 2001, Pegoraro-Krook et al 2004).

Segundo Golding-Kushner (2001) todas as crianças com fissura de palato deveriam ser avaliadas quanto ao desenvolvimento da comunicação por volta dos 8 meses de idade ou preferencialmente antes, quando o balbucio está surgindo, por ser mais fácil e eficaz prevenir do que tratar as alterações de linguagem e fala. Bzoch (2004) afirmou, no entanto, que a fala e a linguagem não podem ser dissociadas no início do desenvolvimento, quando na presença de alterações anátomo-funcionais inerentes à FLP, bem como decorrentes de resultados cirúrgicos insatisfatórios, os quais, em conjunto (a própria fissura e os resultados da tentativa de sua correção), comprometem o funcionamento de orelha média (devido à disfunção tubária), o funcionamento velofaríngeo (devido à disfunção velofaríngea estrutural ou funcional), a aquisição de fala e linguagem (devido a atrasos relacionados a alterações auditivas, alterações na produção de sons, hospitalizações, interação social). 
A fala é o resultado acústico final da linguagem, o sistema de comunicação mais eficiente, o qual engloba aspectos de articulação, fluência e voz. A linguagem é a capacidade de manipular símbolos, sejam eles, verbais, mentais, gráficos, gestuais. Envolve habilidades fonológicas, semânticas, sintáticas e pragmáticas, do ponto de vista receptivo e expressivo. Os processos de atenção, memória, associação, closura, na modalidade visual e auditiva também fazem parte de todo processamento da linguagem. Existem ainda as habilidades da linguagem escrita, as quais são a leitura e a escrita. Neste estudo o enfoque foi nas habilidades de linguagem de indivíduos com FLP e não nos aspectos de sua fala, os quais são amplamente estudados em todo o mundo.

A literatura pesquisada sobre a aquisição e o desenvolvimento da linguagem de indivíduos com fissura labiopalatina mostra a inexistência de estudos nesta área enfocando todos os aspectos da linguagem, do ponto de vista receptivo e expressivo. Poucos estudos referem risco para atraso na aquisição das primeiras palavras, dificuldades lexicais, gramaticais, fonológicas, pragmáticas, dificuldades de compreensão, aprendizagem e memória, mas não aprofundam o tema ou avaliam as habilidades da linguagem diante dos riscos relatados.

O presente estudo permite conhecer o perfil lingüístico de indivíduos com fissura labiopalatina, os quais estão expostos a diversos fatores de risco para desenvolver alterações de comunicação, confirmando a importância de caracterizar o perfil das habilidades de linguagem nesta população. 


\section{OBJETIVO.}

O objetivo do presente trabalho foi caracterizar o perfil das habilidades de linguagem (oral e escrita) e habilidades auditivas e visuais de indivíduos com FLP, entre 7 e 9 anos de idade. Para isso foram avaliadas clinicamente as seguintes variáveis: semântica, sintaxe, fonologia, pragmática; e complementarmente: memória auditiva e visual, associação auditiva e visual, closura gramatical e visual, recepção da linguagem, vocabulário receptivo, processamento fonológico, escrita, aritmética, leitura, processamento auditivo e atenção auditiva. 


\section{MATERIAL E MÉTODOS.}

O projeto foi encaminhado ao Comitê de Ética em Pesquisa do HRAC, segundo as determinações do Conselho Nacional de Saúde (Resolução 196/96) e recebeu sua aprovação em 5 de junho de 2007, conforme ofício 122/2007-SVAPEPE-CEP (anexo1). Recebeu apoio do Conselho Nacional de Desenvolvimento Científico e Tecnológico - CNPQ (Edital Universal Processo 475531/2007-8).

\section{1 Casuística.}

Inicialmente foi realizado o levantamento dos pacientes com auxílio da assistente social do HRAC, para verificar quais indivíduos tinham agendamento nos próximos 12 meses, prazo determinado para a coleta de dados. Dos indivíduos selecionados foram elencados os que apresentavam idade entre 7 e 9 anos, com possibilidade de horário extra para a realização da pesquisa. Entretanto, muitos indivíduos não puderam fazer parte do estudo por apresentar, no momento da entrevista, otites, rolhas de cera, perfuração da membrana timpânica, diagnosticados pelo otorrinolaringologista, perdas auditivas diagnosticados pela avaliação audiológica e incompatibilidade de horários para a realização das avaliações, já que os pacientes freqüentemente, ficavam apenas um dia na cidade.

Novos levantamentos foram feitos e de um universo de 62 indivíduos, 24 compuseram a amostra, com idades entre 7 e 9 anos de idade, regularmente matriculados no HRAC com diagnóstico prévio de FLP. A idade foi definida por não haver, nesta faixa etária, trabalhos na literatura relacionados à linguagem em indivíduos com FLP, além de ser uma faixa etária em que todos os subsistemas lingüísticos (semântico, pragmático, fonológico, sintático) já foram adquiridos, no entanto, continuam a ser aprimorados. Nesta faixa etária também já seria possível 
avaliar a linguagem escrita.

Os pais e os indivíduos foram convidados a participar da pesquisa e ao aceitarem foram esclarecidos quanto aos objetivos e todos os procedimentos clínicos aos quais as crianças seriam submetidas. Foram cumpridos todos os critérios éticos para a execução deste projeto, incluindo a assinatura do Termo de Consentimento Livre e Esclarecido (anexo 2), por parte do familiar responsável, após leitura do mesmo.

Para a seleção dos participantes foram considerados os seguintes critérios de inclusão:

- Apresentar diagnóstico prévio de FLP transforame incisivo unilateral (direita ou esquerda), sem outras malformações, seqüências associadas ou síndromes genéticas;

- Estar na faixa etária entre sete e nove anos de idade.

Os critérios de exclusão utilizados foram:

- Quadro de otite;

- Perda auditiva de leve a moderada; sensórioneural, mista ou condutiva;

- Deficiência visual (visão subnormal);

- Deficiência intelectual.

Inicialmente foi realizado um estudo piloto com cinco indivíduos, submetidos às mesmas avaliações clínicas e formais a fim de calibrar a metodologia a ser aplicada no projeto.

Embora tenha-se buscado uma visão integral dos indivíduos, os resultados da pesquisa foram descritos em partes para melhor visualização e compreensão.

\subsection{Procedimentos.}

\subsubsection{Entrevista.}

Cada criança passou por observação clínica e entrevista com os familiares responsáveis, contendo informações a respeito de possíveis queixas, história pregressa das queixas, 
antecedentes familiais, período gestacional, nascimento, pós-nascimento (saúde geral, desenvolvimento neuropsicomotor e lingüístico) e tratamentos realizados.

Foram considerados como antecedentes gestacionais e perinatais relevantes, aqueles ocorridos no primeiro trimestre de gestação ou no período peri conceptual. Nos antecedentes familiais, enfatizou-se a presença ou ausência de consangüinidade entre os genitores, recorrência na irmandade ou parentes próximos, casos na família, isolados ou com recorrência, de outros distúrbios da comunicação e gemelaridade.

\subsubsection{Análise de Prontuário.}

Para complementação dos dados da entrevista com os pais foi realizada análise nos prontuários, visando caracterizar a amostra. Os dados coletados fizeram referência à localização de origem dos pacientes, classificação socioeconômica da família do participante utilizada pelo HRAC (Graciano et al 1996), articulação, ressonância, gravidade do comprometimento da inteligibilidade de fala, voz e fluência.

Os achados de articulação, ressonância, gravidade do comprometimento da inteligibilidade de fala, voz e fluência foram classificados por fonoaudiólogos do HRAC, segundo os critérios de Williams et al (1998).

\subsubsection{Avaliação Fonoaudiológica.}

A avaliação fonoaudiológica dividiu-se em observação clínica e avaliação complementar. A observação clínica foi realizada pelo pesquisador englobando os componentes pragmático, semântico, sintático e fonológico da linguagem oral, do ponto de vista receptivo e expressivo.

\section{Observação Fonoaudiológica Clínica}

Optou-se por usar o termo observação clínica já que esta foi realizada em uma única 
sessão, devido à pouca disponibilidade de horário dos indivíduos pelos agendamentos marcados.

A observação do aspecto fonológico ocorreu em atividades de fala, nomeação espontânea e dirigida, discriminação auditiva. A amostra foi avaliada por meio da análise de processos fonológicos (Lowe 1996). Quando o repertório fonológico estava completo foi considerado adequado, na presença de processos de simplificação foi designado dificuldade.

A sintaxe da linguagem oral refere-se ao uso das regras gramaticais, compreensão de frases e narrativas. Foi avaliada observando a produção de enunciados simples e complexos (duas ou mais frases), presença de elementos frasais, descrição de fatos em seqüência, narrativa. Quanto à recepção avaliou-se compreensão de narrativas, ordens simples e complexas (duas ou mais ações). Os critérios para a análise foram: presença da habilidade, considerada adequada; na ausência ou déficit da habilidade designou-se dificuldade.

A análise semântica avaliou compreensão e uso do significado de palavras, nomeação, definição e função de objetos, durante situações espontâneas e dirigidas. Quando a habilidade estava presente foi considerada adequada, quando ausente ou com déficit foi designada dificuldade.

Para observação clínica da pragmática foram considerados os comportamentos relativos à utilização da comunicação, por meio da habilidade do indivíduo responder às questões solicitadas de forma coerente, iniciar, manter e participar da atividade, de forma verbal ou gestual. Situações de fala encadeada e dirigida foram as estratégias utilizadas para a observação. Quando a habilidade pragmática estava preservada foi considerada adequada, para ausência ou déficit designou-se dificuldade.

A linguagem receptiva foi considerada adequada quando se observou normalidade na recepção de todas as habilidades (fonologia, semântica, sintaxe, pragmática); foi considerada dificuldade quando encontrou-se déficit na recepção de uma ou mais habilidades. 
A análise dos resultados da observação clínica foi baseada em estudos de vários pesquisadores que delimitaram o desenvolvimento normal da linguagem a partir do nascimento, com dados de crianças brasileiras, espanholas, francesas e norte-americanas (Crystal 1981, Aguado 1989, Chiari et al 1991, Perissinoto 1992, Yavas et al 1992, Pérez 1995, Santana e Acosta 1996, Fletcher e MacWhinney 1997, Lamprecht, 2004).

\section{Avaliação Fonoaudiológica Complementar}

Os testes e as provas a seguir foram utilizados como complementação dos achados da observação clínica.

\section{Teste Illinois de Habilidades Psicolingüísticas (ITPA)}

Este teste foi utilizado para avaliar habilidades relacionadas ao processo de comunicação. Engloba 12 subtestes que avaliaram a recepção auditiva e visual, a memória seqüencial visual e auditiva, a associação auditiva e visual, a "closura" visual, auditiva e gramatical, a expressão verbal e manual e a combinação de sons. O Teste Illinois de Habilidades Psicolingüísticas permitiu quantificar e comparar o desempenho dos indivíduos estudados em tarefas que envolviam habilidades fundamentais relacionadas ao processo de comunicação. Este teste foi elaborado por Kirk e McCarthy (1961) e fundamenta-se no referencial teórico da psicolingüística neobehaviorista, principalmente nas bases teóricas de Osgood (1957). O estudo da adaptação do ITPA à língua portuguesa foi realizado em duas teses de mestrado (Bogossian 1975, Santos 1977), utilizando a edição revisada, publicada em 1968 (Kirk et al 1968). Informações sobre a adaptação brasileira do teste foram apresentadas em um manual para o examinador publicado por Bogossian e Santos (1977).

A utilização do ITPA é recomendada para avaliar crianças entre 2 e 10 anos e 11 meses de 
idade cronológica ou mental. O Teste Illinois de Habilidades Psicolingüísticas é composto por 12 subtestes, que avaliam as habilidades psicolingüísticas, com base nos processos de comunicação, conforme descrito por Giacheti (1996). No trabalho em questão serão utilizados 6 subtestes, a saber:

Subteste 3 - Memória seqüencial visual: avalia a habilidade de reproduzir, memorizando seqüências de figuras desprovidas de significado. Por questões práticas, a avaliação da memória se restringe à memória imediata. As 17 figuras apresentadas são abstratas e as reproduções das seqüências são apresentadas em progressão de complexidade. A apresentação das figuras dividese em 25 seqüências, variando, em extensão, de 2 a 8 figuras.

Subteste 4 - Associação auditiva: objetiva avaliar a habilidade para relacionar conceitos apresentados oralmente, por meio de analogias verbais. Compreende 42 analogias, em que o primeiro par de elementos está associado a uma relação que deverá ser apreendida para ser utilizada no segundo par, em que está presente apenas o primeiro elemento.

Subteste 5 - Memória seqüencial auditiva: analisa a habilidade para reproduzir, memorizando seqüências de dígitos progressivamente maiores. Envolve memória imediata. Consta de vinte e oito seqüências, que variam, em extensão, de 2 a 8 dígitos.

Subteste 6 - Associação visual: objetiva avaliar a habilidade para lidar com analogias visuais. Descreve a capacidade para relacionar estímulos visualmente recebidos, por meio da compreensão de seu significado. As analogias requerem noções de diferentes conceitos, tais como: funcionais associações da parte com o todo e vice-versa, similaridade, ações, entre outros.

Subteste 7 - "Closura" visual: objetiva avaliar a capacidade para identificar um estímulo comum, a partir de uma apresentação visual incompleta, reconhecendo o todo através das partes. O subteste compõe-se de 4 cenas, apresentadas separadamente, cada qual contendo 14 ou 15 objetos, conceitualmente semelhantes e apresentados pictoricamente dentro de um limite de 
tempo.

Subteste 9 - "Closura" gramatical: analisa a habilidade para fazer uso de redundâncias da linguagem oral na aquisição da sintaxe e inflexões gramaticais. Consta de 33 itens apresentados oralmente, utilizando gravuras que representam as questões expostas. Engloba o conhecimento de aspectos morfológicos, tais como: flexões de gênero, número e grau; formas verbais de modo, tempo, pessoa e voz e aspectos sintáticos da utilização de conectivos, pronomes e outros.

Após a aplicação, a contagem dos escores (respostas dos indivíduos) obtidos em cada subteste foi realizada e posteriormente utilizamos as tabelas propostas pelo manual do teste que configuravam os seguintes valores:

- $\quad$ Escore bruto obtido: número de acertos obtidos em cada subteste;

- Escore escalar obtido: conseguido em tabelas específicas, por meio do valor do escore bruto, de acordo com a idade cronológica;

- Idade psicolingüística: valor obtido a partir do escore bruto de cada subteste em tabela específica do teste;

Em etapa posterior, realizando o raciocínio inverso nas tabelas, foi determinado o valor esperado, segundo a idade dos indivíduos avaliados.

Foram consideradas adequadas as habilidades cujo escore escalar foi acima de 36 pontos, conforme refere o manual do examinador (Bogossian e Santos 1977).

\section{Teste de Vocabulário Por Imagens Peabody (TVIP)}

O Teste de Vocabulário por Imagens Peabody, adaptação hispanoamericana, de Dunn et al (1986), teve por objetivo avaliar o desenvolvimento lexical no domínio receptivo. Ele fornece avaliação objetiva, rápida e precisa do vocabulário receptivo-auditivo em uma ampla variedade de áreas. As áreas incluíram: pessoas, ações, qualidades, partes do corpo, tempo, natureza, 
lugares, objetivos, animais, ferramentas e instrumentos e termos matemáticos. O TVIP consiste de cinco pranchas de teste, organizadas em ordem crescente de dificuldades. Cada prancha é composta por quatro desenhos de linha preta em fundo branco. O teste é organizado de acordo com um modelo de múltipla escolha. Não requer que o examinando leia, escreva ou verbalize. A tarefa do examinado foi selecionar a figura que melhor representasse a palavra falada pelo examinador. É um teste indicado para avaliar o nível de desenvolvimento da linguagem receptiva em pré-escolares e em crianças ou adultos que não lêem que não escrevam e que não falem. Como propõe a análise estatística do manual do teste, o vocabulário receptivo foi classificado em 7 categorias: extremamente alta; moderadamente alta; média alta; média; média baixa; moderadamente baixa e extremamente baixa. Foram considerados normais aqueles indivíduos que apresentaram classificação extremamente alta; moderadamente alta; média alta; média; média baixa.

\section{TESTE TOKEN}

O Teste Token foi utilizado para avaliar a linguagem receptiva. Desde sua versão original desenvolvida por De Renzi e Vignolo (1962), tem sido utilizado em estudos para avaliar as habilidades lingüísticas em diferentes populações clínicas, como afásicos, disléxicos, entre outros. Originalmente era composto por 62 instruções com um aumento gradual de dificuldade em cada item. Em 1978, De Renzi e Faglioni desenvolveram uma forma resumida de aplicação com 36 itens, que é a versão que será utilizada neste estudo. O teste é composto por 20 peças que variam em formatos geométricos (círculo e quadrado), dos tamanhos (grande e pequeno) e quatro cores (preto, vermelho, amarelo e branco). O aplicador deverá obedecer à seqüência de 36 instruções que são divididas em seis partes (anexo 3): a parte A consta de 7 instruções, as partes de B a E constam de quatro instruções cada uma e a parte F consta de 13 instruções. Nas partes 
$\mathrm{B}$, D e F, as peças pequenas se cobrem com pedaço de papel, e as instruções só fazem referências as peças grandes. As partes apresentam um aumento sucessivo de dificuldade, porém dentro de cada parte todas as instruções evidenciam o mesmo nível de dificuldade. Para cada instrução obedecida corretamente, o indivíduo consegue um ponto. A pontuação máxima conseguida no teste é de 36 pontos. Os resultados são classificados em: dificuldade grave, dificuldade moderada, dificuldade leve, média inferior, média, média superior. Foram considerados adequados os indivíduos que apresentaram classificação média inferior, média, média superior.

\section{PeRFIL das habilidades FONOLÓGICAS (PHF)}

Este instrumento foi desenvolvido no Brasil por Carvalho, Alvarez e Caetano (1998) e objetiva fornecer dados sobre a capacidade do indivíduo em processar os aspectos fonológicos da língua.

O PHF é constituído pelos itens que identificam e compõem as habilidades fonológicas de análise, adição, segmentação, subtração, substituição, rimas, rima seqüencial, reversão silábica e imagem articulatório; e pode ser aplicado em crianças de 5 a 10 anos de idade, sendo que os itens que avaliam o nível fonêmico só são aplicados em crianças acima de 7 anos.

No início de cada item há uma ordem e um modelo pré-estabelecidos. No modelo, as duas primeiras citações são utilizadas para demonstrar a tarefa. Entendida a atividade, a criança deve então responder os quatro itens selecionados. Caso a criança apresente dificuldade em trabalhar o nível auditivo abstrato, deve-se auxiliá-la com pistas concretas (material utilizado como mediador visual).

Nos itens análise inicial, segmentação vocabular, recepção de rimas, rima seqüencial e imagem articulatória os acertos contam 2 pontos, enquanto nas provas de análise final e média, adição de sílabas e fonemas, segmentação frasal, subtração de sílabas e fonemas, substituição e 
reversão silábica, a contagem positiva será de um ponto. Em caso de erro é assinalado o valor 0 . Esses valores são somados no final de cada item e ao término da aplicação para a obtenção dos escores totais. De acordo com o escore apresentado, o resultado é classificado em esperado ou sob atenção.

\section{Teste do Desempenho Escolar (TDE)}

O Teste de Desempenho Escolar (TDE) teve por objetivo avaliar as capacidades fundamentais para o desempenho escolar, mais especificamente da escrita, aritmética e leitura. Este teste será realizado apenas nas crianças alfabetizadas. Os resultados foram anotados em protocolo específico e constaram de tarefas como escrita sob ditado, contas de matemática e resoluções de problemas apresentados verbalmente pelo examinador e leitura. Os achados foram analisados em tabelas específicas com tratamento estatístico, propostas pelo manual do teste (Stein 1994).

Como parte do processo de avaliação fonoaudiológica, a avaliação audiológica constou inicialmente de uma parte básica contendo:

- Inspeção otológica clínica: a fim de verificar a existência de impedimento para a realização da avaliação audiológica.

- Audiometria Tonal Liminar (ATL) e Imitanciometria.

$\mathrm{O}$ diagnóstico audiológico foi obtido mediante a análise criteriosa dos resultados. $\mathrm{O}$ critério de normalidade utilizado como referência para ATL foi classificado segundo Davis e Silverman (1970).

A configuração da curva timpanométrica foi classificada de acordo com Jerger (1970): TIPO A; TIPO B; TIPO C; TIPO Ar e TIPO Ad.

As crianças que não apresentaram normalidade na avaliação audiológica básica, ou seja, 
audição periférica abaixo (pior) de $20 \mathrm{~dB}$, foram excluídas do estudo e as que apresentaram audição normal foram submetidas à avaliação do processamento auditivo e atenção auditiva.

As crianças que não participaram do estudo foram submetidas à mesma observação clínica e avaliação complementar e emitidos relatórios conclusivos das avaliações realizadas.

\section{Avaliação Fonoaudiológica do Processamento Auditivo e Atenção Auditiva}

A avaliação do Processamento Auditivo é um procedimento utilizado para diagnosticar o uso funcional correto e eficiente da audição nos indivíduos de diferentes faixas etárias (Pereira 1997). Esta avaliação foi realizada por um fonoaudiólogo colaborador. Os testes utilizados foram: Teste de detecção de intervalos aleatórios de silêncio (Randon Gap Detection Test - RGDT), proposto por Keith (2000). Consiste na apresentação gravada de uma sequência de pares de tons puros nas freqüências de 500,1000, 2000 e $4000 \mathrm{~Hz}$, com intervalos entre os dois tons que variam de 0 a $40 \mathrm{~ms}(0,2,5,10,15,20,25,30$ e $40 \mathrm{~ms})$, apresentados de forma aleatória. A habilidade avaliada foi a resolução temporal. Utilizou-se os subtestes 1 (para prendizagem), o subteste 2 (padrão) e o subteste 3 (expandido). As respostas foram registradas em protocolo apropriado. Após a aprendizagem, e no caso da criança detectar intervalos iguais ou menores a 40 ms, deu-se continuidade para medir as freqüências de 500, 1000, 2000 e $4000 \mathrm{~Hz}$. Uma vez, que a criança não identificou nenhum dos intervalos como dois tons, deu-se continuidade utilizando o RGDT-Expandido, medindo as mesmas freqüências, porém com intervalos de até $300 \mathrm{~ms}$. O resultado do RGDT foi medido por meio do menor intervalo a partir do qual o indivíduo passou a identificar a presença de dois estímulos. Foi calculado individualmente para cada freqüência, de 500 a $4.000 \mathrm{~Hz}$, bem como a média de resultados das quatro freqüências. Keith (2000) em seu trabalho original encontrou um tempo de detecção de intervalo de tempo (gap detection), considerado normal quando, menor que $20 \mathrm{~ms}$. 
Teste Dicótico de Dígitos, proposto por Santos e Pereira (1997), constituído por 20 pares de dígitos, sendo que estes representam dissílabos na língua portuguesa, apresentados 2 pares em cada orelha simultaneamente. São apresentados em 2 tarefas: tarefa de integração binaural e tarefa de separação binaural. Este teste avaliou a habilidade para agrupar componentes do sinal acústico em figura fundo e identificá-los, e a comunicação inter-hemisférica no corpo caloso, na tarefa de integração binaural. Neste estudo foi realizada apenas a etapa de integração binaural. Considerou-se erro quando um dígito foi omitido ou substituído. Como valores de normalidade foram considerados $95 \%$ de acertos ou mais em cada orelha para os de idade igual ou maiores de 9 anos e de $85 \%$ à direita e $82 \%$ à esquerda para os de idade de 7 e 8 anos (Boscariol et al 2009).

No Teste Dicótico Não Verbal, proposto por Ortiz e Pereira (1997), foram apresentados 6 sons não-verbais, combinados aos pares e apresentados 2 pares em cada orelha simultaneamente. Foi apresentado em três etapas de atenção. Na etapa de atenção livre o indivíduo deveria prestar atenção e apontar uma das figuras que representasse o som mais facilmente ouvido. Na etapa de atenção à direita, o indivíduo deveria apontar a figura que correspondesse ao som ouvido na orelha direita, ignorando o som apresentado na orelha oposta; na etapa de atenção à esquerda, o indivíduo deveria apontar a figura que correspondesse ao som ouvido na orelha esquerda, ignorando o som apresentado na orelha oposta. Este teste avaliou a habilidade de atenção seletiva para sons não verbais. No Teste Dicótico Não Verbal considerou-se normalidade quando as três etapas de atenção mostraram-se adequadas, e considerou-se como dificuldade quando uma ou mais etapas estavam defasadas.

Teste da Habilidade de Atenção Auditiva Sustentada (THAAS) (Feniman 2004), constituído por 600 palavras monossilábicas (100 monossílabos apresentados seis vezes, sem interrupção) gravadas e apresentadas à criança de maneira binaural, a qual deveria levantar a mão apenas para uma palavra alvo estipulada (palavra "não"). Avaliou a habilidade de atenção 
sustentada e vigilância auditiva. Para verificar a habilidade de atenção auditiva sustentada por meio do teste THAAS, considerou-se a pontuação total e o cálculo do decréscimo de vigilância. A pontuação total é obtida pela soma entre os erros de desatenção (quando a criança não levantou a mão em resposta à palavra alvo "não") e de impulsividade (quando a criança levantou a mão para outra palavra ao invés da palavra "não"). O decréscimo da vigilância, isto é, o declínio na atenção no teste é obtido pela subtração entre o número de respostas corretas respondidas para a palavra "não" na $1^{\mathrm{a}}$ apresentação e o número de respostas corretas na $6^{\mathrm{a}}$ apresentação. Calculou-se o percentil para demonstrar a ocorrência do decréscimo de vigilância. A obtenção de valores inferiores a 10\% é sugestiva de problemas de atenção auditiva sustentada.

O desempenho das crianças nos testes foi classificado em: dificuldade, quando as crianças não atingiram os escores esperado para a idade em qualquer uma das orelhas e condições competitivas propostos pelos autores, e normalidade, quando atingido.

\subsubsection{Avaliação Cognitiva.}

A avaliação cognitiva foi realizada por um psicólogo com o objetivo de descartar possíveis alterações associadas quanto à inteligência geral. Foi utilizado o Teste Matrizes Progressivas Coloridas de Raven (Raven 1998). O instrumento caracteriza-se por um caderno composto por três séries (A, AB e B) cada uma contendo 12 itens, um em cada folha. Cada item constitui-se de desenhos, com um pedaço faltante, possibilitando apenas uma resposta correta. $\mathrm{O}$ indivíduo é solicitado completá-lo, escolhendo entre seis alternativas a que ele acredita ser correta. A aplicação desse instrumento se deu conforme as instruções contidas em seu manual em todas as crianças, sendo de aplicação coletiva quando indicado. Segundo os autores do manual, o instrumento possui validade de constructo fornecida pela diferenciação da idade cronológica, sendo evidenciado um aumento das médias com a idade, o que, conforme Anastasi (1967) pode 
ser considerado como evidência. Na avaliação do teste atribui-se um ponto a cada resposta certa, sendo a pontuação total dos indivíduos fornecida pelo número de acertos. Os itens A1 e A2, por serem usados como exemplos, não são computados na análise. Na tabela 1 está apresentada a classificação proposta pelo teste de acordo com o escore obtido.

Tabela 1 - Classificação proposta de acordo com o escore obtido utilizado na presente pesquisa (Angelini AL et al. Manual Matrizes Progressivas Coloridas de Raven - Escala Especial. São Paulo: Centro Editor de Testes e Pesquisas em Psicologia, 1999).

\begin{tabular}{clc}
\hline Grau & \multicolumn{1}{c}{ Interpretação } & $\begin{array}{c}\text { Faixa de percentis } \\
\text { para o grupo de idade }\end{array}$ \\
\hline I & $\begin{array}{l}\text { "intelectualmente superior" } \\
\text { II }\end{array}$ & $\mathbf{9 5}$ ou superior \\
"definidamente acima da média & $\mathbf{7 5 - 9 4}$ \\
& na capacidade intelectual" & \\
& II+ & $90-94$ \\
III & "intelectualmente médio" & $\mathbf{2 6 - 7 4}$ \\
& III- & $50-74$ \\
IV & "definidamente abaixo da média & $26-49$ \\
na capacidade intelectual” & $\mathbf{6 - 2 5}$ \\
IV- & "intelectualmente deficiente" & $6-10$ \\
\end{tabular}

\subsubsection{Análise dos Resultados.}

Os dados foram analisados qualitativamente (freqüência absoluta (n) e freqüência relativa (\%)) e quantitativamente (média, desvio padrão, mediana, valor mínimo e valor máximo). Para a estatística inferencial foi usado teste de qui-quadrado ou o teste exato de Fisher (Agresti, 1990) e coeficiente de correlação de Pearson (Neter et al., 1996), com disposição dos resultados em tabelas e gráficos. Em todos os testes foi adotado nível de significância de 5\% $(p<0,05)$. 


\section{RESULTADOS.}

Entre os indivíduos que fizeram parte do estudo não houve nenhuma desistência, mesmo após a explicação do caráter voluntário da pesquisa. Todos os indivíduos avaliados receberam relatório conclusivo das avaliações realizadas, conforme descrito no Termo de Consentimento Livre e Esclarecido. Além disso, uma cópia do relatório também foi anexada ao prontuário do paciente no HRAC.

\subsection{Descrição da casuística.}

A amostra constituiu-se por crianças de 7 anos (38\%), 8 anos (21\%) e por crianças de 9 anos $(42 \%)$ de idade, sendo $54 \%$ do gênero feminino e $46 \%$ do gênero masculino; 8 pacientes (33\%) eram provenientes do estado de São Paulo, 6 (25\%) de Minas Gerais e os demais de outros estados: Mato Grosso do Sul (2 pacientes), Rio de Janeiro (2 pacientes), Rio Grande do Sul (2 pacientes), Santa Catarina (2 pacientes), Distrito Federal (1 paciente) e Goiás (1 paciente).

A maior parte dos pacientes (92\%) pertencia ao nível socioeconômico baixo, sendo 38\% baixo inferior e $54 \%$ baixo superior, os demais $8 \%$ pertenciam ao nível socioeconômico médio inferior, de acordo com a classificação de Graciano et al (1996).

De acordo com os dados coletados 5 pacientes (21\%) cursavam a $1^{\text {a }}$ série; 7 (29\%) estavam matriculados na $2^{\mathrm{a}}$ série; $9(38 \%)$ na $3^{\mathrm{a}}$ série e 3 crianças $(13 \%)$ cursavam a $4^{\mathrm{a}}$ série do ensino fundamental (Anexo 4).

\subsection{Achados da entrevista e observação clínica.}

Segundo o relato obtido por meio da entrevista $84 \%$ dos indivíduos com FLP que compuseram a amostra apresentaram episódios de otite, sendo 42\% episódios recorrentes; $38 \%$ 
das mães apresentaram queixas fonoaudiológicas atuais com relação a seus filhos. De forma geral as crianças analisadas eram comunicativas, estabeleciam diálogos com a avaliadora, mostraramse participativas, disponíveis para a avaliação. Os dados de cada criança estão descritos em anexo (Anexo 6). Na tabela 2 estão sintetizados os resultados obtidos por meio da observação clínica segundo o desempenho nas habilidades da linguagem oral (fonologia, semântica, sintaxe, pragmática).

Tabela 2. Desempenho nas habilidades de linguagem oral por meio da observação clínica.

\begin{tabular}{cccccc}
\hline Indivíduo & Fonologia & Sintaxe & Semântica & Pragmática & Recepção \\
\hline $\mathbf{1}$ & Adequado & Adequado & Adequado & Adequado & Adequado \\
$\mathbf{2}$ & Adequado & Dificuldade & Dificuldade & Dificuldade & Dificuldade \\
$\mathbf{3}$ & Adequado & Adequado & Adequado & Adequado & Dificuldade \\
$\mathbf{4}$ & Adequado & Dificuldade & Dificuldade & Dificuldade & Dificuldade \\
$\mathbf{5}$ & Adequado & Adequado & Adequado & Adequado & Dificuldade \\
$\mathbf{6}$ & Dificuldade & Dificuldade & Dificuldade & Dificuldade & Dificuldade \\
$\mathbf{7}$ & Adequado & Dificuldade & Dificuldade & Dificuldade & Dificuldade \\
$\mathbf{8}$ & Adequado & Adequado & Dificuldade & Adequado & Dificuldade \\
$\mathbf{9}$ & Dificuldade & Adequado & Adequado & Adequado & Adequado \\
$\mathbf{1 0}$ & Adequado & Dificuldade & Dificuldade & Dificuldade & Dificuldade \\
$\mathbf{1 1}$ & Adequado & Dificuldade & Dificuldade & Dificuldade & Dificuldade \\
$\mathbf{1 2}$ & Adequado & Adequado & Adequado & Adequado & Adequado \\
$\mathbf{1 3}$ & Dificuldade & Dificuldade & Dificuldade & Dificuldade & Dificuldade \\
$\mathbf{1 4}$ & Dificuldade & Adequado & Adequado & Adequado & Dificuldade \\
$\mathbf{1 5}$ & Adequado & Adequado & Adequado & Adequado & Adequado \\
$\mathbf{1 6}$ & Adequado & Adequado & Adequado & Adequado & Adequado \\
$\mathbf{1 7}$ & Adequado & Adequado & Adequado & Adequado & Adequado \\
$\mathbf{1 8}$ & Adequado & Adequado & Adequado & Adequado & Adequado \\
$\mathbf{1 9}$ & Adequado & Adequado & Adequado & Adequado & Adequado \\
$\mathbf{2 0}$ & Dificuldade & Dificuldade & Dificuldade & Dificuldade & Dificuldade \\
$\mathbf{2 1}$ & Adequado & Adequado & Adequado & Adequado & Adequado \\
$\mathbf{2 2}$ & Adequado & Adequado & Adequado & Adequado & Adequado \\
$\mathbf{2 3}$ & Adequado & Adequado & Adequado & Dificuldade & Dificuldade \\
$\mathbf{2 4}$ & Adequado & Adequado & Adequado & Adequado & Adequado \\
\hline
\end{tabular}

\subsection{Achados do prontuário}

Na tabela 3 estão apresentados os dados referentes à articulação, ressonância, gravidade 
da ininteligibilidade de fala, voz e fluência, obtidos com os dados constantes nos prontuários.

Tabela 3. Desempenho de fala dos indivíduos da amostra.

\begin{tabular}{|c|c|c|c|c|c|}
\hline Indivíduo & Articulação & Ressonância & $\begin{array}{c}\text { Gravidade da } \\
\text { Ininteligibilidade }\end{array}$ & Voz & Fluência \\
\hline 1 & DDO & Hipernasal & $\begin{array}{l}\text { Moderada para } \\
\text { severa }\end{array}$ & Adequada & Adequada \\
\hline 2 & DDO & Adequada & Leve & Adequada & Adequada \\
\hline 3 & DDO & Adequada & Leve & Adequada & Adequada \\
\hline 4 & $\mathrm{DDO}, \mathrm{DAC}$ & Hipernasal & $\begin{array}{l}\text { Moderada para } \\
\text { severa }\end{array}$ & Adequada & Adequada \\
\hline 5 & DDO & Hipernasal & Leve & Adequada & Adequada \\
\hline 6 & DDO, DAC & Hipernasal & $\begin{array}{l}\text { Leve para } \\
\text { moderada }\end{array}$ & Rouca & Adequada \\
\hline 7 & DDO & Adequada & Leve & Adequada & Adequada \\
\hline 8 & DDO & Hipernasal & $\begin{array}{l}\text { Leve para } \\
\text { moderada }\end{array}$ & Adequada & Adequada \\
\hline 9 & DDO & Adequada & $\begin{array}{l}\text { Leve para } \\
\text { Moderada }\end{array}$ & Adequada & Adequada \\
\hline 10 & DDO & Adequada & $\begin{array}{l}\text { Leve para } \\
\text { moderada }\end{array}$ & Adequada & Adequada \\
\hline 11 & DDO & Adequada & Leve & Adequada & Adequada \\
\hline 12 & DDO & Adequada & Leve & Adequada & Adequada \\
\hline 13 & Adequada & Adequada & Adequada & Adequada & Adequada \\
\hline 14 & DDO & Hipernasal & Moderada & Adequada & Adequada \\
\hline 15 & DDO & Adequada & Leve & Adequada & Adequada \\
\hline 16 & Adequada & Adequada & Adequada & Adequada & Adequada \\
\hline 17 & DDO & Hipernasal & Leve & Adequada & Adequada \\
\hline 18 & DAC & Moderada & Moderada & $\begin{array}{l}\text { Rouca } \\
\text { soprosa }\end{array}$ & Adequada \\
\hline 19 & DAC & Hipernasal & $\begin{array}{l}\text { Moderada para } \\
\text { severa }\end{array}$ & Adequada & Adequada \\
\hline 20 & $\mathrm{DAC}$ & Hipernasal & $\begin{array}{l}\text { Moderada para } \\
\text { severa }\end{array}$ & Rouca & Adequada \\
\hline 21 & DDO, DAC & Adequada & Moderada & Rouca & Adequada \\
\hline 22 & DDO & Adequada & $\begin{array}{l}\text { Leve para } \\
\text { moderada }\end{array}$ & Rouca & Adequada \\
\hline 23 & DDO & Hipernasal & Leve & Adequada & Adequada \\
\hline 24 & DDO & Leve & Leve & Adequada & Adequada \\
\hline
\end{tabular}

Legenda: DDO: distúrbio dento-oclusal (projeção de língua, sigmatismo, distorção oro-lateral, alteração do ponto articulatório) DAC: distúrbio articulatório compensatório 


\subsection{Avaliação Complementar.}

a) Teste Illinois de Habilidades Psicolingüísticas - ITPA

$\mathrm{Na}$ comparação entre as idades cronológicas dos indivíduos e as idades psicolingüísticas obtidas por meio do teste, verificou-se que a habilidade com maior número de dificuldades entre os indivíduos avaliados foi a associação auditiva, seguida pela associação visual, closura visual e memória auditiva. As crianças apresentaram maior número de acertos nas habilidade de memória visual e closura gramatical. Os resultados estão descritos na tabela 4. 
Tabela 4. Desempenho nos subtestes do ITPA.

\begin{tabular}{|c|c|c|c|c|c|c|c|c|c|c|c|c|c|c|c|c|c|c|c|}
\hline \multirow[t]{2}{*}{ Indivíduo } & \multirow[t]{2}{*}{ IC } & \multicolumn{3}{|c|}{ Associação Auditiva } & \multicolumn{3}{|c|}{ Associação Visual } & \multicolumn{3}{|c|}{ Closura Gramatical } & \multicolumn{3}{|c|}{ Closura Visual } & \multicolumn{3}{|c|}{ Memória Auditiva } & \multicolumn{3}{|c|}{ Memória Visual } \\
\hline & & EB & EE & IPL & EB & $\mathbf{E E}$ & IPL & EB & EE & IPL & EB & $\mathbf{E E}$ & IPL & EB & $\mathbf{E E}$ & IPL & EB & EE & IPL \\
\hline 1 & $7,4 a$ & 30 & 40 & $8,6 \mathrm{a}$ & 19 & 37 & $7,6 a$ & 24 & 39 & $8,3 \mathrm{a}$ & 22 & 41 & $10,11 \mathrm{a}$ & 43 & 48 & $10,11 \mathrm{a}$ & 20 & 42 & $10,11 \mathrm{a}$ \\
\hline 2 & $7,9 a$ & 29 & 39 & $8,3 \mathrm{a}$ & 13 & 35 & $5,0 \mathrm{a}$ & 22 & 37 & $7,4 a$ & 18 & 37 & $7,6 \mathrm{a}$ & 33 & 42 & $10,11 \mathrm{a}$ & 21 & 44 & $10,11 \mathrm{a}$ \\
\hline 3 & $8,10 \mathbf{a}$ & 23 & 29 & 6,0a & 20 & 36 & $8,0 \mathrm{a}$ & 26 & 39 & $9,4 \mathrm{a}$ & 25 & 42 & $10,11 \mathrm{a}$ & 33 & 41 & $10,11 \mathrm{a}$ & 21 & 43 & $10,11 \mathrm{a}$ \\
\hline 4 & $7,4 a$ & 13 & 24 & $3,8 \mathrm{a}$ & 17 & 35 & 6,6a & 14 & 30 & $4,7 \mathrm{a}$ & 17 & 36 & 7,0a & 13 & 29 & $3,6 \mathrm{a}$ & 11 & 30 & $4,6^{\mathrm{a}}$ \\
\hline 5 & $9,4 a$ & 31 & 36 & $9,0 \mathrm{a}$ & 31 & 45 & $10,11 \mathrm{a}$ & 27 & 38 & $9,11 \mathrm{a}$ & 38 & 50 & $10,11 \mathrm{a}$ & 26 & 35 & $8,0 \mathrm{a}$ & 29 & 49 & $10,11 \mathrm{a}$ \\
\hline 6 & $8,2 a$ & 23 & 29 & 6,0a & 21 & 37 & $8,6 a$ & 30 & 43 & $10,6 \mathrm{a}$ & 21 & 38 & $10,0 \mathrm{a}$ & 38 & 45 & $10,11 \mathrm{a}$ & 25 & 49 & $10,11 \mathrm{a}$ \\
\hline 7 & $9,1 \mathrm{a}$ & 28 & 33 & $8,0 \mathrm{a}$ & 11 & 25 & $4,4 \mathrm{a}$ & 24 & 35 & $8,3 \mathrm{a}$ & 15 & 32 & $6,0 \mathrm{a}$ & 31 & 39 & $10,11 \mathrm{a}$ & 18 & 36 & $9,0 \mathrm{a}$ \\
\hline 8 & $7,10 \mathrm{a}$ & 21 & 32 & $5,6 \mathrm{a}$ & 14 & 32 & $5,4 \mathrm{a}$ & 23 & 38 & 7,9a & 16 & 35 & 6,6a & 25 & 37 & $7,6 \mathrm{a}$ & 09 & 27 & $4,0 \mathrm{a}$ \\
\hline 9 & $\mathbf{7 , 6 a}$ & 34 & 44 & $10,11 \mathrm{a}$ & 17 & 35 & $6,6 a$ & 28 & 43 & $10,6 a$ & 17 & 36 & $7,0 \mathrm{a}$ & 41 & 47 & $10,11 \mathrm{a}$ & 25 & 49 & $10,11 \mathrm{a}$ \\
\hline 10 & $9,2 a$ & 18 & 24 & $4,9 \mathrm{a}$ & 10 & 24 & $4,0 \mathrm{a}$ & 25 & 36 & $8,9 a$ & 23 & 37 & $10,11 \mathrm{a}$ & 21 & 31 & 6,0a & 21 & 40 & $10,11 \mathrm{a}$ \\
\hline 11 & $9,2 a$ & 44 & 45 & $10,11 \mathrm{a}$ & 30 & 44 & $10,11 \mathrm{a}$ & 22 & 33 & 7,4a & 27 & 42 & $10,11 \mathrm{a}$ & 23 & 33 & $6,8 \mathrm{a}$ & 21 & 40 & $10,11 \mathrm{a}$ \\
\hline 12 & 9,9a & 35 & 40 & $10,11 \mathrm{a}$ & 25 & 39 & $10,11 \mathrm{a}$ & 33 & 44 & $10,6 \mathrm{a}$ & 39 & 50 & $10,11 \mathrm{a}$ & 43 & 47 & $10,11 \mathrm{a}$ & 37 & 55 & $10,11 \mathrm{a}$ \\
\hline 13 & $9,4 a$ & 24 & 30 & $6,6 a$ & 23 & 37 & $9,6 \mathrm{a}$ & 22 & 33 & $7,4 a$ & 21 & 37 & $10,0 \mathrm{a}$ & 12 & 25 & $3,3 a$ & 18 & 36 & $9,0 \mathrm{a}$ \\
\hline 15 & $9,8 a$ & 39 & 44 & $10,11 \mathrm{a}$ & 26 & 40 & $10,11 \mathrm{a}$ & 31 & 42 & $10,11 \mathrm{a}$ & 24 & 39 & $10,11 \mathrm{a}$ & 38 & 44 & $10,11 \mathrm{a}$ & 33 & 54 & $10,11 \mathrm{a}$ \\
\hline 16 & $9,2 \mathrm{a}$ & 37 & 42 & $10,11 \mathrm{a}$ & 30 & 44 & $10,11 \mathrm{a}$ & 32 & 43 & $10,6 a$ & 18 & 34 & $7,6 \mathrm{a}$ & 39 & 44 & $10,11 \mathrm{a}$ & 18 & 36 & $9,0 \mathrm{a}$ \\
\hline 17 & $8,8 a$ & 30 & 38 & $8,6 a$ & 23 & 38 & $9,6 a$ & 31 & 44 & $10,6 a$ & 32 & 49 & $10,11 \mathrm{a}$ & 17 & 30 & $4,8 \mathrm{a}$ & 22 & 44 & $10,11 \mathrm{a}$ \\
\hline 18 & $7,2 a$ & 23 & 33 & $6,0 \mathrm{a}$ & 14 & 32 & $5,4 \mathrm{a}$ & 23 & 38 & 7,9a & 16 & 35 & 6,6a & 24 & 48 & $10,11 \mathrm{a}$ & 40 & 47 & $10,11 \mathrm{a}$ \\
\hline 19 & $9,6 a$ & 35 & 40 & $10,11 \mathrm{a}$ & 25 & 39 & $10,11 \mathrm{a}$ & 29 & 40 & $10,6 a$ & 26 & 41 & $10,11 \mathrm{a}$ & 55 & 53 & $10,11 \mathrm{a}$ & 14 & 31 & 6,0a \\
\hline 20 & $7,5 a$ & 11 & 22 & $3,4 \mathrm{a}$ & 09 & 27 & $3,9 \mathrm{a}$ & 20 & 35 & 6,6a & 05 & 24 & $2,8 \mathrm{a}$ & 25 & 37 & 7,6a & 16 & 37 & $7,9 a$ \\
\hline 21 & $8,11 \mathrm{a}$ & 27 & 34 & $7,6 \mathrm{a}$ & 27 & 42 & $10,11 \mathrm{a}$ & 28 & 41 & $10,6 \mathrm{a}$ & 19 & 36 & $8,0 \mathrm{a}$ & 42 & 48 & $10,11 \mathrm{a}$ & 19 & 40 & $10,0 \mathrm{a}$ \\
\hline 22 & $8,7 a$ & 16 & 20 & $4,3 \mathrm{a}$ & 20 & 36 & $8,0 \mathrm{a}$ & 28 & 41 & $10,6 \mathrm{a}$ & 23 & 40 & $10,11 \mathrm{a}$ & 33 & 41 & $10,11 \mathrm{a}$ & 21 & 43 & $10,11 \mathrm{a}$ \\
\hline 23 & $7,6 a$ & 24 & 34 & $6,6 \mathrm{a}$ & 19 & 37 & 7,6a & 25 & 40 & $8,9 a$ & 25 & 44 & $10,11 \mathrm{a}$ & 17 & 32 & $4,8 \mathrm{a}$ & 20 & 42 & $10,11 \mathrm{a}$ \\
\hline 24 & $9,0 a$ & 33 & 38 & $10,0 \mathrm{a}$ & 24 & 38 & $10,0 \mathrm{a}$ & 32 & 43 & $10,6 a$ & 30 & 45 & $10,11 \mathrm{a}$ & 53 & 53 & $10,11 \mathrm{a}$ & 19 & 37 & $10,0 \mathrm{a}$ \\
\hline
\end{tabular}

Legenda: 


\section{b) Teste de Vocabulário por Imagens - Peabody (TVIP)}

Por meio dos resultados exibidos na tabela 5 observa-se que 2 crianças (8\%) apresentaram no TVIP classificação extremamente baixa, 1 criança (4\%) teve classificação moderadamente baixa e 1 criança (indivíduo 20) não obteve base para a realização do teste, mostrando um desempenho muito aquém do esperado para sua idade, totalizando $16 \%$ da amostra com resultados rebaixados no vocabulário receptivo. As demais crianças apresentaram classificação entre média baixa e extremamente alta, perfazendo um total de $84 \%$ da amostra com resultados dentro do esperado para a faixa etária.

Tabela 5. Classificação no TVIP.

\begin{tabular}{ccc} 
Indivíduo & Pontuação Standard & Classificação \\
\hline $\mathbf{1}$ & 104 & Média alta \\
$\mathbf{2}$ & 91 & Média baixa \\
$\mathbf{3}$ & 101 & Média \\
$\mathbf{4}$ & 89 & Média baixa \\
$\mathbf{5}$ & 101 & Média \\
$\mathbf{6}$ & 93 & Média baixa \\
$\mathbf{7}$ & 60 & Extremamente baixa \\
$\mathbf{8}$ & 95 & Média \\
$\mathbf{9}$ & 114 & Moderadamente alta \\
$\mathbf{1 0}$ & 61 & Extremamente baixa \\
$\mathbf{1 1}$ & 104 & Média alta \\
$\mathbf{1 2}$ & 130 & Extremamente alta \\
$\mathbf{1 3}$ & 78 & Moderadamente baixa \\
$\mathbf{1 4}$ & 108 & Média alta \\
$\mathbf{1 5}$ & 139 & Extremamente alta \\
$\mathbf{1 6}$ & 110 & Média alta \\
$\mathbf{1 7}$ & 110 & Média alta \\
$\mathbf{1 8}$ & 111 & Média alta \\
$\mathbf{1 9}$ & 110 & Média alta \\
$\mathbf{2 0}$ & - & - \\
$\mathbf{2 1}$ & 106 & Média alta \\
$\mathbf{2 2}$ & 104 & Média alta \\
$\mathbf{2 3}$ & 116 & Moderadamente alta \\
$\mathbf{2 4}$ & 110 & Média alta \\
\hline
\end{tabular}




\section{c) Teste Token}

Os resultados da tabela 6 permitem observar que 13 crianças (54\%) apresentaram no Teste Token resultados rebaixados na habilidade de compreensão oral, sendo 1 (4\%) com dificuldade muito grave, $3(13 \%)$ com dificuldade moderada, 2 (8\%) com dificuldade média e 7 (29\%) com dificuldade leve. As demais (46\%) apresentaram compreensão oral adequada.

Tabela 6. Classificação no Teste Token.

\begin{tabular}{ccc}
\hline Indivíduo & Escore & Classificação \\
\hline $\mathbf{1}$ & 35,06 & Média superior \\
$\mathbf{2}$ & 31,06 & Média inferior \\
$\mathbf{3}$ & 26,76 & Dificuldade leve \\
$\mathbf{4}$ & 0 & Dificuldade muito grave \\
$\mathbf{5}$ & 31,76 & Média inferior \\
$\mathbf{6}$ & 26,76 & Dificuldade leve \\
$\mathbf{7}$ & 23,76 & Dificuldade moderada \\
$\mathbf{8}$ & 23,86 & Dificuldade moderada \\
$\mathbf{9}$ & 32,86 & Média \\
$\mathbf{1 0}$ & 26,76 & Dificuldade leve \\
$\mathbf{1 1}$ & 26,26 & Dificuldade leve \\
$\mathbf{1 2}$ & 32,66 & Média \\
$\mathbf{1 3}$ & 28,76 & Dificuldade leve \\
$\mathbf{1 4}$ & 31,56 & Média inferior \\
$\mathbf{1 5}$ & 35,66 & Média superior \\
$\mathbf{1 6}$ & 31,76 & Média inferior \\
$\mathbf{1 7}$ & 25,76 & Dificuldade leve \\
$\mathbf{1 8}$ & 32,36 & Dificuldade média \\
$\mathbf{1 9}$ & 31,46 & Média inferior \\
$\mathbf{2 0}$ & 22,56 & Dificuldade moderada \\
$\mathbf{2 1}$ & 29,06 & Média inferior \\
$\mathbf{2 2}$ & 29,26 & Média inferior \\
$\mathbf{2 3}$ & 27,56 & Dificuldade leve \\
$\mathbf{2 4}$ & 32,26 & Dificuldade média \\
\hline
\end{tabular}




\section{d) Perfil de Habilidades Fonológicas (PHF)}

Pode-se observar na tabela 7 que $63 \%$ das crianças avaliadas por meio do PHF apresentaram normalidade nas habilidades fonológicas e 38\% da amostra tiveram resultados inferiores aos esperados para sua idade.

Tabela 7. Desempenho no PHF.

\begin{tabular}{ccc}
\hline Indivíduo & Pontuação & Classificação \\
\hline $\mathbf{1}$ & 67 & Esperado \\
$\mathbf{2}$ & 62 & Esperado \\
$\mathbf{3}$ & 66 & Esperado \\
$\mathbf{4}$ & 22 & Sob atenção \\
$\mathbf{5}$ & 61 & Esperado \\
$\mathbf{6}$ & 58 & Esperado \\
$\mathbf{7}$ & 58 & Esperado \\
$\mathbf{8}$ & 49 & Sob atenção \\
$\mathbf{9}$ & 54 & Sob atenção \\
$\mathbf{1 0}$ & 64 & Esperado \\
$\mathbf{1 1}$ & 48 & Sob atenção \\
$\mathbf{1 2}$ & 74 & Esperado \\
$\mathbf{1 3}$ & 52 & Sob atenção \\
$\mathbf{1 4}$ & 51 & Sob atenção \\
$\mathbf{1 5}$ & 71 & Esperado \\
$\mathbf{1 6}$ & 73 & Esperado \\
$\mathbf{1 7}$ & 69 & Esperado \\
$\mathbf{1 8}$ & 67 & Esperado \\
$\mathbf{1 9}$ & 70 & Esperado \\
$\mathbf{2 0}$ & 24 & Sob atenção \\
$\mathbf{2 1}$ & 57 & Esperado \\
$\mathbf{2 2}$ & 69 & Esperado \\
$\mathbf{2 3}$ & 57 & Esperado \\
$\mathbf{2 4}$ & 73 & Esperado \\
\hline
\end{tabular}




\section{e) Teste do Desempenho Escolar (TDE)}

Observou-se no resultado final do TDE que 50\% da amostra (12 indivíduos) apresentaram escore inferior, 4\% (1 indivíduo) tiveram escore médio inferior, 25\% (6 indivíduos) escore médio, 8\% (2 indivíduos) escore médio superior e 12\% (3 indivíduos) tiveram escore superior. Pôde-se verificar ainda desempenho rebaixado em escrita em 58\% dos indivíduos e em aritmética e leitura escore rebaixado em $42 \%$ da amostra (tabela 8 ).

Tabela 8. Desempenho no TDE.

\begin{tabular}{ccccccccc}
\hline Indivíduo & Escrita & Classif & Aritmética & Classif & Leitura & Classif & Total & Classif \\
\hline $\mathbf{1}$ & 7 & MI & 7 & MS & 60 & MS & 74 & MS \\
$\mathbf{2}$ & 14 & I & 3 & M & 62 & M & 89 & M \\
$\mathbf{3}$ & 22 & M & 9 & I & 61 & M & 92 & M \\
$\mathbf{4}$ & 1 & I & 2 & I & 0 & I & 3 & I \\
$\mathbf{5}$ & 19 & I & 11 & I & 66 & M & 96 & I \\
$\mathbf{6}$ & 5 & I & 10 & I & 36 & I & 51 & I \\
$\mathbf{7}$ & 21 & I & 11 & I & 60 & I & 92 & I \\
$\mathbf{8}$ & 5 & MI & 4 & MI & 43 & MS & 52 & MI \\
$\mathbf{9}$ & 10 & MI & 8 & MS & 55 & MS & 73 & MS \\
$\mathbf{1 0}$ & 14 & I & 18 & S & 66 & M & 98 & I \\
$\mathbf{1 1}$ & 9 & I & 12 & I & 46 & I & 67 & I \\
$\mathbf{1 2}$ & 24 & I & 21 & M & 66 & M & 111 & I \\
$\mathbf{1 3}$ & 14 & I & 11 & M & 69 & S & 94 & M \\
$\mathbf{1 4}$ & 6 & I & 8 & I & 53 & I & 67 & I \\
$\mathbf{1 5}$ & 29 & M & 19 & M & 70 & S & 118 & M \\
$\mathbf{1 6}$ & 29 & M & 14 & I & 65 & I & 108 & M \\
$\mathbf{1 7}$ & 13 & I & 16 & M & 33 & I & 62 & I \\
$\mathbf{1 8}$ & 31 & S & 14 & S & 68 & S & 113 & S \\
$\mathbf{1 9}$ & 28 & M & 22 & M & 67 & M & 117 & M \\
$\mathbf{2 0}$ & 1 & I & 2 & I & 0 & I & 3 & I \\
$\mathbf{2 1}$ & 10 & I & 10 & M & 52 & I & 72 & I \\
$\mathbf{2 2}$ & 31 & S & 19 & S & 69 & S & 119 & S \\
$\mathbf{2 3}$ & 11 & I & 9 & I & 53 & I & 73 & I \\
$\mathbf{2 4}$ & 33 & S & 18 & S & 67 & M & 118 & S \\
\hline
\end{tabular}

Legenda: M: médio I: inferior $\quad$ S: superior MI: médio inferior $\quad$ MS: médio superior Classif: classificação

Nas tabelas 9 e 10 estão apresentados os resumos da avaliação complementar, para melhor visualização. 
Tabela 9. Desempenho na avaliação complementar.

\begin{tabular}{|c|c|c|c|c|c|c|c|c|c|c|}
\hline \multirow{2}{*}{ Ind } & \multicolumn{6}{|c|}{ ITPA - EE } & \multirow{2}{*}{ TVIP } & \multirow{2}{*}{ Token } & \multirow{2}{*}{ PHF } & \multirow{2}{*}{ TDE } \\
\hline & $\mathbf{A A}$ & $\mathbf{A V}$ & CG & $\mathrm{CV}$ & MA & MV & & & & \\
\hline 1 & 40 & 37 & 39 & 41 & 48 & 42 & Média alta & $\begin{array}{l}\text { Média } \\
\text { superior }\end{array}$ & Esperado & $\begin{array}{l}\text { Médio } \\
\text { superior }\end{array}$ \\
\hline 2 & 39 & 35 & 37 & 37 & 42 & 44 & Média baixa & $\begin{array}{l}\text { Média } \\
\text { inferior }\end{array}$ & Esperado & Médio \\
\hline 3 & 29 & 36 & 39 & 42 & 41 & 43 & Média & $\begin{array}{c}\text { Dificuldade } \\
\text { leve }\end{array}$ & Esperado & Médio \\
\hline 4 & 24 & 35 & 30 & 36 & 29 & 30 & Média baixa & $\begin{array}{l}\text { Dificuldade } \\
\text { muito grave }\end{array}$ & $\begin{array}{c}\text { Sob } \\
\text { atenção }\end{array}$ & Inferior \\
\hline 5 & 36 & 45 & 38 & 50 & 35 & 49 & Média & $\begin{array}{l}\text { Média } \\
\text { inferior }\end{array}$ & Esperado & Inferior \\
\hline 6 & 29 & 37 & 43 & 38 & 45 & 49 & Média baixa & $\begin{array}{l}\text { Dificuldade } \\
\text { leve }\end{array}$ & Esperado & Inferior \\
\hline 7 & 33 & 25 & 35 & 32 & 39 & 36 & $\begin{array}{l}\text { Extremamente } \\
\text { baixa }\end{array}$ & $\begin{array}{l}\text { Dificuldade } \\
\text { moderada }\end{array}$ & Esperado & Inferior \\
\hline 8 & 32 & 32 & 38 & 35 & 37 & 27 & Média & $\begin{array}{l}\text { Dificuldade } \\
\text { moderada }\end{array}$ & $\begin{array}{c}\text { Sob } \\
\text { atenção }\end{array}$ & $\begin{array}{l}\text { Médio } \\
\text { inferior }\end{array}$ \\
\hline 9 & 44 & 35 & 43 & 36 & 47 & 49 & $\begin{array}{l}\text { Moderadamente } \\
\text { alta }\end{array}$ & Média & $\begin{array}{c}\text { Sob } \\
\text { atenção }\end{array}$ & $\begin{array}{l}\text { Médio } \\
\text { superior }\end{array}$ \\
\hline 10 & 24 & 24 & 36 & 37 & 31 & 40 & $\begin{array}{c}\text { Extremamente } \\
\text { baixa }\end{array}$ & $\begin{array}{l}\text { Dificuldade } \\
\text { leve }\end{array}$ & Esperado & Inferior \\
\hline 11 & 45 & 44 & 33 & 42 & 33 & 40 & Média alta & $\begin{array}{l}\text { Dificuldade } \\
\text { leve }\end{array}$ & $\begin{array}{c}\text { Sob } \\
\text { atenção }\end{array}$ & Inferior \\
\hline 12 & 40 & 39 & 44 & 50 & 47 & 55 & $\begin{array}{l}\text { Extremamente } \\
\text { alta }\end{array}$ & Média & Esperado & Inferior \\
\hline 13 & 30 & 37 & 33 & 37 & 25 & 36 & $\begin{array}{c}\text { Moderadamente } \\
\text { baixa }\end{array}$ & $\begin{array}{l}\text { Dificuldade } \\
\text { leve }\end{array}$ & $\begin{array}{c}\text { Sob } \\
\text { atenção }\end{array}$ & Médio \\
\hline 14 & 37 & 39 & 38 & 42 & 39 & 40 & Média alta & $\begin{array}{l}\text { Média } \\
\text { inferior }\end{array}$ & $\begin{array}{c}\text { Sob } \\
\text { atenção }\end{array}$ & Inferior \\
\hline 15 & 44 & 40 & 42 & 39 & 44 & 54 & $\begin{array}{l}\text { Extremamente } \\
\text { alta }\end{array}$ & $\begin{array}{l}\text { Média } \\
\text { superior }\end{array}$ & Esperado & Médio \\
\hline 16 & 42 & 44 & 43 & 34 & 44 & 36 & Média alta & $\begin{array}{l}\text { Média } \\
\text { inferior }\end{array}$ & Esperado & Médio \\
\hline 17 & 38 & 38 & 44 & 49 & 30 & 44 & Média alta & $\begin{array}{l}\text { Dificuldade } \\
\text { leve }\end{array}$ & Esperado & Inferior \\
\hline 18 & 33 & 32 & 38 & 35 & 48 & 47 & Média alta & $\begin{array}{l}\text { Dificuldade } \\
\text { média }\end{array}$ & Esperado & Superior \\
\hline 19 & 40 & 39 & 40 & 41 & 53 & 31 & Média alta & $\begin{array}{l}\text { Média } \\
\text { inferior }\end{array}$ & Esperado & Médio \\
\hline 20 & 22 & 27 & 35 & 24 & 37 & 37 & - & $\begin{array}{l}\text { Dificuldade } \\
\text { moderada }\end{array}$ & $\begin{array}{c}\text { Sob } \\
\text { atenção }\end{array}$ & Inferior \\
\hline 21 & 34 & 42 & 41 & 36 & 48 & 40 & Média alta & $\begin{array}{l}\text { Média } \\
\text { inferior }\end{array}$ & Esperado & Inferior \\
\hline 22 & 20 & 36 & 41 & 40 & 41 & 43 & Média alta & $\begin{array}{l}\text { Média } \\
\text { inferior }\end{array}$ & Esperado & Superior \\
\hline 23 & 34 & 37 & 40 & 44 & 32 & 42 & $\begin{array}{l}\text { Moderadamente } \\
\text { alta }\end{array}$ & $\begin{array}{l}\text { Dificuldade } \\
\text { leve }\end{array}$ & Esperado & Inferior \\
\hline 24 & 38 & 38 & 43 & 45 & 53 & 37 & Média alta & $\begin{array}{l}\text { Dificuldade } \\
\text { média }\end{array}$ & Esperado & Superior \\
\hline
\end{tabular}

Legenda: Ind: indivíduo $\quad$ EE: escore escalar $\quad$ AA: associação auditiva $\quad$ AV: associação visual CG: closura gramatical CV: closura visual MA: memória auditiva MV: memória visual 
Tabela 10. Valores da média, desvio-padrão, valores mínimos e máximos e mediana, referentes ao desempenho dos indivíduos na avaliação complementar.

\begin{tabular}{lcccccc}
\hline Variáveis & N & Média & Desvio-padrão & Mínimo & Mediana & Máximo \\
\hline Teste Token & 24 & 28,2 & 7,0 & 0,0 & 29,2 & 35,7 \\
TVIP & 24 & 97,7 & 27,4 & 0,0 & 104,0 & 139,0 \\
PHF & 24 & 59,0 & 13,6 & 22,0 & 61,5 & 74,0 \\
TDE & 24 & 81,8 & 32,3 & 3,0 & 90,5 & 119,0 \\
TDE - Escrita & 24 & 16,1 & 10,2 & 1,0 & 14,0 & 33,0 \\
TDE - Aritmética & 24 & 12,0 & 5,6 & 2,0 & 11,0 & 22,0 \\
TDE - Leitura & 24 & 53,6 & 19,5 & 0,0 & 60,5 & 70,0 \\
ITPA - Associação auditiva & 24 & 34,5 & 7,1 & 20,0 & 35,0 & 45,0 \\
ITPA - Associação visual & 24 & 36,4 & 5,4 & 24,0 & 37,0 & 45,0 \\
ITPA - Closura gramatical & 24 & 38,9 & 3,8 & 30,0 & 39,0 & 44,0 \\
ITPA - Closura visual & 24 & 39,3 & 5,9 & 24,0 & 38,5 & 50,0 \\
ITPA - Memória auditiva & 24 & 40,3 & 7,7 & 25,0 & 41,0 & 53,0 \\
ITPA - Memória visual & 24 & 41,7 & 6,7 & 27,0 & 41,0 & 55,0 \\
\hline
\end{tabular}

\section{f) Processamento Auditivo e Atenção Auditiva}

Considerando a análise dos dados da avaliação do processamento auditivo e atenção auditiva, conforme pode ser observado na tabela 11, verificou-se que no dicótico não verbal 17 indivíduos (71\%) apresentaram dificuldade e 7 (29\%) normalidade nas habilidades de atenção seletiva e figura-fundo auditiva, lembrando-se que foi considerado normalidade apenas quando os resultados das 3 etapas estavam adequados (atenção livre, atenção à direita e atenção à esquerda).

No dicótico de dígitos 11 indivíduos (46\%) apresentaram normalidade e 13 indivíduos (54\%) apresentaram dificuldades, avaliando a habilidade de integração binaural e figura-fundo auditiva, ou seja, atenção dividida. No teste da Habilidade de Atenção Auditiva Sustentada (THAAS) 7 crianças (29\%) mostraram normalidade e 17 indivíduos (71\%) apresentaram 
resultados rebaixados nas habilidades de atenção sustentada e vigilância auditiva. No teste de detecção de intervalos aleatórios de silêncio (Random gap detection test) foram encontradas apenas 4 crianças (17\%) com normalidade e 20 (83\%) com déficit na habilidade de resolução temporal.

Tabela 11. Distribuição dos indivíduos segundo a avaliação do processamento auditivo.

\begin{tabular}{|c|c|c|c|c|c|c|}
\hline Indivíduo & $\begin{array}{l}\text { Dicótico não } \\
\text { verbal atenção } \\
\text { livre }\end{array}$ & $\begin{array}{c}\text { Dicótico } \\
\text { não verbal } \\
\text { atenção à } \\
\text { direita }\end{array}$ & $\begin{array}{l}\text { Dicótico } \\
\text { não verbal } \\
\text { atenção à } \\
\text { esquerda }\end{array}$ & $\begin{array}{l}\text { Dicótico } \\
\text { de dígitos }\end{array}$ & THAAS & $\begin{array}{c}\text { Gap } \\
\text { detection }\end{array}$ \\
\hline 1 & dificuldade & dificuldade & dificuldade & normalidade & dificuldade & normalidade \\
\hline 2 & normalidade & dificuldade & dificuldade & normalidade & dificuldade & dificuldade \\
\hline 3 & dificuldade & normalidade & normalidade & normalidade & normalidade & dificuldade \\
\hline 4 & dificuldade & dificuldade & dificuldade & dificuldade & dificuldade & dificuldade \\
\hline 5 & normalidade & normalidade & normalidade & dificuldade & dificuldade & dificuldade \\
\hline 6 & normalidade & dificuldade & normalidade & dificuldade & dificuldade & dificuldade \\
\hline 7 & normalidade & dificuldade & dificuldade & dificuldade & dificuldade & dificuldade \\
\hline 8 & dificuldade & dificuldade & dificuldade & dificuldade & normalidade & dificuldade \\
\hline 9 & normalidade & normalidade & normalidade & normalidade & dificuldade & dificuldade \\
\hline 10 & dificuldade & normalidade & normalidade & normalidade & dificuldade & normalidade \\
\hline 11 & dificuldade & dificuldade & dificuldade & dificuldade & dificuldade & dificuldade \\
\hline 12 & normalidade & dificuldade & dificuldade & dificuldade & dificuldade & dificuldade \\
\hline 13 & dificuldade & dificuldade & dificuldade & dificuldade & dificuldade & dificuldade \\
\hline 14 & dificuldade & dificuldade & normalidade & normalidade & dificuldade & dificuldade \\
\hline 15 & normalidade & normalidade & normalidade & normalidade & normalidade & dificuldade \\
\hline 16 & dificuldade & normalidade & normalidade & normalidade & normalidade & dificuldade \\
\hline 17 & dificuldade & normalidade & normalidade & dificuldade & dificuldade & dificuldade \\
\hline 18 & dificuldade & dificuldade & dificuldade & normalidade & dificuldade & dificuldade \\
\hline 19 & normalidade & normalidade & normalidade & normalidade & normalidade & normalidade \\
\hline 20 & dificuldade & dificuldade & dificuldade & dificuldade & dificuldade & dificuldade \\
\hline 21 & normalidade & normalidade & normalidade & dificuldade & normalidade & dificuldade \\
\hline 22 & dificuldade & normalidade & normalidade & dificuldade & dificuldade & dificuldade \\
\hline 23 & normalidade & normalidade & normalidade & dificuldade & normalidade & normalidade \\
\hline 24 & normalidade & normalidade & normalidade & normalidade & dificuldade & dificuldade \\
\hline
\end{tabular}




\subsection{Avaliação Cognitiva}

Observou-se na avaliação dos dados da avaliação cognitiva (tabela 12) que $42 \%$ da amostra (10 indivíduos) apresentaram média, 33\% (8 indivíduos) apresentaram classificação definidamente acima da média na capacidade intelectual; 8\% (2 indivíduos) foram classificados como definidamente abaixo da média na capacidade intelectual; e 17\% (4 indivíduos) tiveram classificação intelectualmente superior, conforme pode ser observado na tabela abaixo.

Tabela 12. Distribuição dos indivíduos segundo a avaliação cognitiva.

\begin{tabular}{ccc}
\hline Indivíduo & Percentil & Classificação \\
\hline $\mathbf{1}$ & 95 & Intelectualmente superior \\
$\mathbf{2}$ & 95 & Intelectualmente superior \\
$\mathbf{3}$ & $25-50$ & Intelectualmente médio \\
$\mathbf{4}$ & 50 & Intelectualmente médio \\
$\mathbf{5}$ & $75-90$ & Definidamente acima da média \\
$\mathbf{6}$ & 75 & Definidamente acima da média \\
$\mathbf{7}$ & 50 & Intelectualmente médio \\
$\mathbf{8}$ & $50-75$ & Intelectualmente médio \\
$\mathbf{9}$ & $75-90$ & Definidamente acima da média \\
$\mathbf{1 0}$ & 50 & Intelectualmente médio \\
$\mathbf{1 1}$ & $50-75$ & Intelectualmente médio \\
$\mathbf{1 2}$ & 95 & Intelectualmente superior \\
$\mathbf{1 3}$ & $10-25$ & Definidamente abaixo da média \\
$\mathbf{1 4}$ & 75 & Definidamente acima da média \\
$\mathbf{1 5}$ & 95 & Intelectualmente superior \\
$\mathbf{1 6}$ & $75-90$ & Definidamente acima da média \\
$\mathbf{1 7}$ & $75-90$ & Definidamente acima da média \\
$\mathbf{1 8}$ & 75 & Intelectualmente médio \\
$\mathbf{1 9}$ & $50-75$ & Intelectualmente médio \\
$\mathbf{2 0}$ & 26 & Definidamente abaixo da média \\
$\mathbf{2 1}$ & 75 & Definidamente acima da média \\
$\mathbf{2 2}$ & $50-75$ & Intelectualmente médio \\
$\mathbf{2 3}$ & $50-75$ & Intelectualmente médio \\
$\mathbf{2 4}$ & $75-90$ & Definidamente acima da média \\
\hline
\end{tabular}

A seguir estão apresentados os resultados obtidos entre as variáveis do processamento auditivo e as demais variáveis. 
Pode-se perceber que em todos os resultados houve correlação, mas esta foi significativa $(p<0,05)$ somente entre o teste Dicótico de dígitos, o qual avalia integração binaural e figurafundo auditiva, e o Teste Token $(p=0,037)$, o Dicótico de dígitos e o ITPA no subteste de associação auditiva ( $p=0,043)$, o Dicótico de dígitos e o TDE $(p=0,037)$, o Dicótico de dígitos e a escrita do TDE $(p=0,011)$ e o Dicótico de dígitos e a leitura do TDE $(p=0,047)$, conforme pode ser observado na tabela 13 .

Tabela 13. Valores de p dos testes de qui-quadrado ou do teste exato de Fisher (em itálico) para estudar a associação entre as variáveis do processamento auditivo e as demais variáveis.

\begin{tabular}{ccccccc}
\hline Variável independente & $\begin{array}{c}\text { Dicótico não } \\
\text { verbal } \\
\text { atenção livre }\end{array}$ & $\begin{array}{c}\text { Dicótico } \\
\text { não verbal } \\
\text { atenção à } \\
\text { direita }\end{array}$ & $\begin{array}{c}\text { Dicótico } \\
\text { não verbal } \\
\text { atenção à } \\
\text { esquerda }\end{array}$ & $\begin{array}{c}\text { Dicótico } \\
\text { de } \\
\text { dígitos }\end{array}$ & THAAS & GAP \\
\hline TVIP & 0,596 & 0,590 & 0,272 & 0,596 & 0,283 & 0,544 \\
Teste Token & 0,205 & 0,413 & 0,408 & $\mathbf{0 , 0 3 7 *}$ & 1,000 & 1,000 \\
PHF & 0,423 & 0,089 & 0,092 & 0,423 & 0,191 & 0,259 \\
ITPA - Associação auditiva & 0,706 & 1,000 & 0,697 & $\mathbf{0 , 0 4 3 *}$ & 1,000 & 1,000 \\
ITPA - Associação visual & 0,656 & 1,000 & 0,408 & 0,706 & 0,386 & 0,596 \\
ITPA - Closura gramatical & 0,166 & 0,155 & 0,050 & 0,166 & 0,130 & 1,000 \\
ITPA - Closura visual & 1,000 & 1,000 & 0,403 & 1,000 & 1,000 & 0,259 \\
ITPA - Memória visual & 0,649 & 0,640 & 0,192 & 0,649 & 0,307 & 1,000 \\
ITPA - Memória auditiva & 0,166 & 1,000 & 0,665 & 0,166 & 0,629 & 0,251 \\
TDE & 0,706 & 1,000 & 0,697 & $\mathbf{0 , 0 3 7 *}$ & 0,386 & 1,000 \\
TDE - Escrita & 0,697 & 0,214 & 0,421 & $\mathbf{0 , 0 1 1 *}$ & 0,085 & 1,000 \\
TDE - Aritmética & 0,697 & 0,679 & 1,000 & 0,240 & 1,000 & 0,615 \\
TDE - Leitura & 0,697 & 0,679 & 1,000 & $\mathbf{0 , 0 4 7 *}$ & 1,000 & 0,615 \\
RAVEN & 1,000 & 1,000 & 0,417 & 1,000 & 1,000 & 1,000 \\
\hline & $* p<0,05$ diferença estatisticamente significante & &
\end{tabular}

A tabela 14 mostra os intervalos de confiança dos coeficientes de correlação entre os dados do desempenho escolar (TDE) e os demais instrumentos complementares de avaliação. 
Verificou-se correlação significativa entre o TDE e: TVIP, Teste Token, PHF, ITPA nos subtestes de closura gramatical e memória auditiva.

Tabela 14. Estimativas e intervalos de confiança dos coeficientes de correlação de Pearson (r) entre os resultados do TDE e os demais resultados da avaliação complementar.

\begin{tabular}{clccc}
\hline \multirow{2}{*}{ Variável 1 } & \multicolumn{1}{c}{ Variável 2 } & r & \multicolumn{2}{c}{ Intervalo de confiança (95\%) } \\
\cline { 4 - 5 } TDE & TVIP & $\mathbf{0 , 5 3}$ & $\mathbf{0 , 1 6}$ & $\mathbf{0 , 7 7}$ \\
& Teste Token & $\mathbf{0 , 7 1}$ & $\mathbf{0 , 4 2}$ & $\mathbf{0 , 8 6}$ \\
& PHF & $\mathbf{0 , 8 9}$ & $\mathbf{0 , 7 5}$ & $\mathbf{0 , 9 5}$ \\
& ITPA - Associação auditiva & 0,35 & $-0,06$ & 0,66 \\
ITPA - Associação visual & 0,23 & $-0,19$ & 0,58 \\
& ITPA - Closura gramatical & $\mathbf{0 , 4 5}$ & $\mathbf{0 , 0 5}$ & $\mathbf{0 , 7 2}$ \\
ITPA - Closura visual & 0,39 & $-0,02$ & 0,68 \\
& ITPA - Memória visual & 0,22 & $-0,20$ & 0,57 \\
& ITPA - Memória auditiva & $\mathbf{0 , 4 3}$ & $\mathbf{0 , 0 4}$ & $\mathbf{0 , 7 1}$
\end{tabular}

Os dados da avaliação cognitiva mostraram que $67 \%$ dos indivíduos apresentaram resultados satisfatórios na capacidade intelectual e 33\% (8 indivíduos) foram classificados como definidamente abaixo da média. Verificou-se correlação significativa entre o Raven e os seguintes instrumentos de avaliação: TVIP, PHF, ITPA nos subtestes de associação auditiva, closura gramatical, closura visual e memória auditiva, como pode ser visto na tabela 15 . 
Tabela 15. Estimativas e intervalos de confiança dos coeficientes de correlação de Pearson (r) entre a avaliação cognitiva e a avaliação complementar.

\begin{tabular}{llccc}
\hline \multirow{2}{*}{ Variável 1 1 Variável 2 } & r & \multicolumn{2}{c}{ Intervalo de confiança (95\%) } \\
\cline { 4 - 5 } & & $\mathbf{0 , 6 4}$ & $\mathbf{0 , 3 1}$ & $\mathbf{0 , 8 3}$ \\
RAVEN & TVIP & 0,40 & $-0,01$ & 0,69 \\
& Teste Token & $\mathbf{0 , 4 6}$ & $\mathbf{0 , 0 6}$ & $\mathbf{0 , 7 3}$ \\
& PHF & $\mathbf{0 , 6 2}$ & $\mathbf{0 , 2 9}$ & $\mathbf{0 , 8 2}$ \\
ITPA - Associação auditiva & 0,40 & $-0,01$ & 0,69 \\
ITPA - Associação visual & 0,0 imferior & Limite superior \\
ITPA - Closura gramatical & $\mathbf{0 , 6 0}$ & $\mathbf{0 , 2 5}$ & $\mathbf{0 , 8 1}$ \\
ITPA - Closura visual & $\mathbf{0 , 4 1}$ & $\mathbf{0 , 0 1}$ & $\mathbf{0 , 7 0}$ \\
ITPA - Memória visual & 0,57 & 0,21 & 0,79 \\
ITPA - Memória auditiva & $\mathbf{0 , 5 0}$ & $\mathbf{0 , 1 2}$ & $\mathbf{0 , 7 5}$ \\
TDE & 0,25 & $-0,17$ & 0,59 \\
TDE - Escrita & 0,19 & $-0,23$ & 0,55 \\
TDE - Aritmética & 0,29 & $-0,12$ & 0,62 \\
TDE - Leitura & 0,23 & $-0,19$ & 0,58
\end{tabular}




\section{DISCUSSÃO}

Dificuldades fonéticas em indivíduos com fissura labiopalatina são amplamente estudadas por pesquisadores em todo o mundo. No Brasil poucos estudos descrevem a importância da fonologia na produção de fala destas crianças e não foram encontrados estudos sobre o desenvolvimento de linguagem, considerando todas as habilidades lingüísticas (sintaxe, semântica, fonologia e pragmática).

Pesquisas indicam alterações da produção da fala, linguagem e de compreensão presentes em crianças com fissura, tendo estas, maior predisposição para apresentar atraso na aquisição das primeiras palavras, na produção de sentenças curtas, dificuldade na recuperação de palavras, na compreensão da linguagem e deficiência no raciocínio, quando comparadas com seus pares com desenvolvimento normal (McWilliams et al 1990, Eliason e Richman 1990, Richman e Eliason 1995, Scherer e D’Antonio1995, Jocelyn et al 1996, Schönweiler et al 1999, Pamplona et al 2000a, Speltz et al 2000, Golding-Kushner 2001, Melgaço et al 2002, Morris e Ozanne 2003, Sharp et al 2003, Pegoraro-Krook et al 2004, Grunwell e Sell 2005).

As crianças avaliadas na presente pesquisa tinham entre 7 e 9 anos de idade, período em que se espera aquisição completa das habilidades de linguagem oral. A partir dos 7 anos a criança aprimora suas habilidades lingüísticas adquiridas nas fases iniciais de seu desenvolvimento (Crystal 1981, Aguado 1989, Chiari et al 1991, Perissinoto 1992, Yavas et al 1992, Pérez 1995, Santana e Acosta 1996, Fletcher e MacWhinney 1997, Lamprecht, 2004).

A linguagem oral dos indivíduos com FLP foi avaliada de acordo com suas habilidades: fonologia, semântica, sintaxe e pragmática. De acordo com os resultados obtidos verificou-se que as crianças com FLP apresentaram em média bom desempenho cognitivo-lingüístico. Na 
observação clínica dez indivíduos apresentaram normalidade na expressão de todos os componentes da linguagem oral, tanto do ponto de vista receptivo quanto expressivo. As demais quatorze crianças mostraram dificuldade em uma ou mais habilidades da linguagem oral. Duas crianças (indivíduos 13 e 20) mostraram dificuldades lingüísticas graves, tanto na recepção quanto na expressão de todas as habilidades, também apresentaram déficit em todas as habilidades avaliadas do processamento auditivo e atenção auditiva e capacidade intelectual abaixo da média. Nestes casos pode-se sugerir uma relação existente entre dificuldade cognitiva e problemas de linguagem.

A fonologia foi avaliada em atividades de fala, nomeação espontâneas e dirigidas, discriminação auditiva. A amostra foi analisada considerando os processos fonológicos (Lowe 1996). A fonologia foi a habilidade lingüística com maior porcentagem de normalidade na observação clínica (79\%), entretanto, de acordo com a literatura esperava-se aquisição completa dos sons da língua até no máximo aos 7 anos (Lamprecht 2004, Andrade et al 2001), ressaltandose, portanto, transtorno fonológico em cinco crianças com FLP avaliadas (indivíduos 6, 9, 13, 14, 20), concordando com os achados de Pamplona et al (2000b). Grunwell e Sell (2005) ressaltaram a possibilidade de comprometimento fonológico nesta população devido aos prejuízos na sinalização de diferenças significantes entre os sons da fala.

O inventário fonológico das crianças evidenciou a presença de processos fonológicos não mais esperados para a faixa etária em 5 indivíduos $(6,9,13,14,20)$; os processos encontrados foram: ensurdecimento de plosivas, ensurdecimento de fricativas, sonorização de plosiva, posteriorização de fricativa, frontalização de nasal, simplificação de consoante final, simplificação de líquidas, simplificação de encontros consonantais. Corroborando os achados deste estudo Pamplona et al (2000b) verificaram a necessidade de diagnosticar e intervir de forma diferenciada nos problemas de fala de crianças com fissura de palato unilateral e comprovaram 
tempo reduzido de intervenção quando esta tinha uma abordagem fonológica e não puramente fonética-articulatória.

Os dados obtidos na avaliação complementar das habilidades fonológicas (PHF), mostraram dificuldade em sete crianças (indivíduos 4, 8, 9, 11, 13, 14, 20). A memória auditiva, outra habilidade do processamento fonológico, foi avaliada objetivamente por meio do subteste de memória auditiva do ITPA e observou-se dificuldade nos indivíduos 4, 5, 10, 11, 13, 17, 23. Ressaltando-se, assim, que quatro das cinco crianças com dificuldade na habilidade fonológica expressiva, na observação clínica, mostraram dificuldades no PHF, sendo estes os indivíduos 9 , 13, 14, 20; apenas uma criança (indivíduo 13) apresentou déficit fonológico na observação clínica e na memória auditiva no ITPA. Outras 3 crianças apresentaram dificuldades no PHF e na memória auditiva no ITPA (indivíduos 4, 11, 13), no entanto, os indivíduos 4 e 11 exibiram fonologia expressiva adequada na observação clínica. As crianças com dificuldades no processamento fonológico, consciência fonológica e memória auditiva, necessitam de maiores cuidados quanto à aprendizagem, conforme orienta a ASHA (2001). Richman e Eliason (1984) observaram baixo desempenho em associação de linguagem, memória auditiva de curto prazo e compreensão de leitura em crianças com fissura de palato em idade escolar entre 8 e 13 anos, confirmando os achados desta pesquisa.

A habilidade sintática foi avaliada segundo o uso das regras gramaticais, compreensão de frases e narrativas. Observou-se a produção de enunciados simples e complexos (duas ou mais frases), presença de elementos frasais, descrição de fatos em seqüência, narrativa. Obteve-se, então, 67\% de normalidade na observação clínica. As crianças com déficit nesta habilidade mostraram dificuldades na elaboração de sentenças complexas e narrativas, bem como no uso de regras gramaticais adequadas. Na avaliação complementar, com o subteste de closura gramatical do ITPA, encontrou-se $75 \%$ de resultados adequados. Os indivíduos 2 e 6 apresentaram 
normalidade na avaliação complementar, entretanto, na observação clínica responderam às questões da avaliadora por meio de monossílabos, apresentaram uma fala bastante simples, elaboração verbal pobre.

A habilidade semântica estava defasada na observação clínica em nove indivíduos, tendo sido considerada a compreensão e uso do significado de palavras, nomeação, definição e função de objetos, corroborando os achados de Pamplona et al (2000a) e Grunwell e Sell (2005), os quais referiram prejuízos para o desenvolvimento semântico em crianças com FLP. Por meio do TVIP encontrou-se déficit no vocabulário receptivo em quatro crianças; destacando-se, portanto, maior dificuldade para a emissão com relação ao aspecto semântico, quando comparada à recepção. Os indivíduos 12 e 15 destacaram-se por seu excelente nível semântico, bem como nas demais habilidades da linguagem oral; na avaliação cognitiva apresentaram capacidade intelectual superior, reforçando a relação entre as habilidades cognitivas e lingüísticas.

Para observação clínica da pragmática foram considerados os comportamentos relativos à utilização da comunicação, por meio da habilidade do indivíduo responder às questões solicitadas de forma coerente, iniciar, manter e participar da atividade, de forma verbal ou gestual, por meio de situações de fala encadeada e dirigida. A observação clínica mostrou $63 \%$ de normalidade, observando-se habilidades comunicativas adequadas durante as atividades dialógicas propostas pela avaliadora. Observou-se que as crianças que apresentaram déficits na pragmática também mostraram dificuldades associadas nas demais habilidades da linguagem (fonologia, sintaxe, semântica). Eliason e Richman (1990) constataram atraso de linguagem em crianças com FLP entre 5 e 6 anos, observando déficit na habilidade de mediação verbal quando comparadas a crianças sem FLP.

$\mathrm{Na}$ observação clínica, considerando todas as habilidades lingüísticas, os resultados evidenciaram maiores dificuldades no desenvolvimento das habilidades semântica e pragmática. 
Grunwell e Sell (2005) relataram possíveis prejuízos lexicais e sintáticos em indivíduos com transtornos anatômicos ou fisiológicos, como é o caso das crianças avaliadas neste estudo. Concordando com os achados da presente pesquisa Pamplona et al (2000a) constataram déficit na organização lingüística situacional, discursiva e semântica em indivíduos com fissura de palato e articulação compensatória, e justificaram a defasagem no contexto semântico, pois este explora o significado expresso em orações individuais e em seqüência de orações, e indivíduos com problemas na organização lingüística apresentam dificuldades para derivar o significado em nível semântico mais abstrato.

A linguagem receptiva na observação clínica estava adequada em $46 \%$ dos indivíduos avaliados. No Teste Token encontrou-se a mesma porcentagem de adequação na recepção da linguagem. No Raven a capacidade cognitiva verificada estava na média ou acima da média. Na avaliação do processamento e atenção auditiva, no entanto, observou-se dificuldade em todas as habilidades analisadas. Desta forma, sugere-se que dificuldades atencionais e do processamento auditivo podem ter contribuído para a dificuldade observada no Teste Token. Sharp et al (2003) concluíram que crianças com fissuras têm maior predisposição de apresentar dificuldade na compreensão da linguagem e deficiência no raciocínio, concordando com os dados desta pesquisa.

O individuo 4 apresentou capacidade intelectual média e dificuldade evidente em todas as habilidades analisadas na observação clínica, complementar e na avaliação do processamento e atenção auditiva. Sugerindo que a capacidade cognitiva não determinou o baixo desempenho lingüístico neste indivíduo. Dois casos em particular (15 e 19) apresentaram adequado desempenho global na amostra em todas as habilidades avaliadas, exceto na resolução temporal (gap detection) e memória visual (subteste do ITPA), respectivamente. Isoladamente tais habilidades não foram decisivas para causar dificuldades na linguagem oral e escrita, sugerindo 
que outros mecanismos associativos auxiliam no desempenho destes indivíduos.

O indivíduo 13 apresentou classificação definidamente abaixo da média na avaliação cognitiva e dificuldade leve no Teste Token. Cabe ressaltar que tais testes priorizam um canal de habilidade específico, a saber, visual e auditivo, respectivamente. Nos demais testes encontrou-se normalidade nas habilidades visuais e dificuldade em todas as habilidades auditivas avaliadas. Podendo-se sugerir desta forma, que a habilidade visual não foi determinante para a classificação abaixo da média encontrada na avaliação cognitiva. O indivíduo 20 também apresentou classificação definidamente abaixo da média na avaliação cognitiva, bem como déficit em todas as demais habilidades avaliadas na pesquisa, exceto a memória auditiva e visual. Sugere-se, neste caso, que a habilidade lingüística pode estar sendo prejudicada pela dificuldade cognitiva e viceversa.

$\mathrm{Na}$ avaliação complementar, considerando os instrumentos ITPA, TVIP, Teste Token, PHF, encontrou-se normalidade em todas as habilidades avaliadas somente nos indivíduos 1,12 e 15, discordando dos estudos de Neiman e Savage (1997) e Chapman et al (1998), os quais não verificaram risco ou atraso no desenvolvimento da linguagem em crianças com fissura.

Quanto ao desempenho acadêmico 50\% dos indivíduos estavam abaixo da média, sendo que os piores resultados foram obtidos em escrita. Estudos nesta população (Richman e Eliason 1984, Broder et al 1998, ASHA 2005, Goldsberry et al 2006) verificaram aumento do risco de dificuldades de aprendizagem, compreensão de leitura, desempenho abaixo da média e alta freqüência de repetência escolar. Richman et al (2005) constataram dificuldade de leitura relacionada a déficits na memória visual, o que pôde ser confirmado nesta pesquisa em três indivíduos, os quais apresentaram classificação inferior na prova de leitura do TDE e memória visual rebaixada no subteste do ITPA. Também deve-se levar em conta o baixo nível socioeconômico familiar dos indivíduos da amostra, o qual sugere baixo nível educacional. 
Entretanto, não se verificou relação entre o desempenho cognitivo e as habilidades acadêmicas avaliadas por meio do TDE (leitura, aritmética e escrita).

Complementarmente, obteve-se 54\% de acertos no subteste de associação visual do ITPA; $75 \%$ de acertos foram obtidos no subteste de memória visual e $63 \%$ no subteste de closura visual. Das crianças com escore rebaixado no TDE (indivíduos 4, 5, 6, 7, 10, 11, 12, 14, 17, 20, 21, 23), quatro (indivíduos 4, 11, 14, 20) apresentaram dificuldades também nas habilidades fonológicas avaliadas por meio do PHF, apresentando maior risco para problemas de aprendizagem, referentes à leitura e escrita. Os indivíduos 6, 14 e 20 ainda apresentaram simplificações fonológicas na fala.

A tabela 8 mostra o desempenho dos indivíduos quanto à linguagem escrita e a tabela $9 \mathrm{o}$ desempenho geral em toda a avaliação complementar. Quando comparados os dados de normalidade na linguagem oral com os achados da linguagem escrita observou-se que os indivíduos 1 e 15 apresentaram adequação na linguagem oral bem como nas habilidades acadêmicas (escrita, aritmética e leitura).

Na tabela 14 foi possível observar a correlação encontrada entre o TDE e os seguintes instrumentos de avaliação: TVIP, Teste Token, PHF, ITPA nos subtestes de closura gramatical e memória auditiva, sugerindo que os indivíduos com defasagem no desempenho acadêmico (leitura, aritmética e escrita) podem apresentar dificuldades no vocabulário receptivo, na compreensão da linguagem oral, na sintaxe e memória auditiva. Assim, devem-se estimular tais habilidades em indivíduos com desempenho escolar prejudicado possibilitando melhores resultados na aprendizagem.

Uma porcentagem bastante alta $(84 \%)$ das crianças apresentou otites recorrentes, concordando com os achados da literatura (Nunn et al 1995, Melgaço et al 2002, Dixon-Wood 2004, Pegoraro-Krook et al 2004) que referem problemas otológicos e auditivos freqüentes nesta 
população. A literatura relata que as otites recorrentes podem ocasionar comprometimento no processamento auditivo, linguagem e aprendizagem (Moore et al 1986, Golding-Kushner 2001, Pegoraro-Krook et al 2004); no presente estudo 84\% da amostra apresentaram episódios constantes de otite, muitos com necessidade de tratamento cirúrgico. Sugere-se, portanto, que os achados de prejuízo quanto ao uso funcional da audição nos indivíduos avaliados, devem-se à presença de otites nas fases iniciais do desenvolvimento das crianças.

Os dados do processamento auditivo nas habilidades avaliadas mostraram-se defasados em 23 indivíduos (96\%), com variações individuais, sugerindo prejuízo funcional da audição. As habilidades mais prejudicadas foram resolução temporal, atenção sustentada e vigilância auditiva. Lemos et al (2008) encontraram porcentagens de acerto inferiores no grupo com FLP quando comparado ao grupo controle sem fissura, tanto para a orelha direita quanto para a orelha esquerda. Boscariol et al (2009) verificaram que crianças com fissura isolada de palato apresentaram importantes alterações nas habilidades auditivas (95\% dos sujeitos), verificadas por meio do desempenho ruim nos testes comportamentais do processamento auditivo, concordando com os dados deste estudo.

Apenas uma criança apresentou normalidade em todas as habilidades avaliadas no processamento auditivo (indivíduo 19), quinze apresentaram dificuldades em três ou mais testes e oito apresentaram dificuldades em um ou dois testes. Considerando os dez indivíduos com adequação da linguagem oral pela observação clínica, nove apresentaram dificuldade em alguma das habilidades avaliadas no processamento auditivo e atenção auditiva. No ITPA verificaram-se dificuldades em associação auditiva em $54 \%$ da amostra.

De acordo com a análise estatística observada na tabela 13 verificou-se correlação entre o dicótico de dígitos e o Teste Token, associação auditiva do ITPA, leitura e escrita do TDE, sugerindo que os indivíduos com dificuldades para agrupar componentes do sinal acústico em 
figura fundo e identificá-los, e para realizar a comunicação inter-hemisférica no corpo caloso, na tarefa de integração binaural, podem apresentar maiores dificuldades na compreensão verbal, associação auditiva, leitura e escrita. As dificuldades encontradas nas habilidades do processamento auditivo avaliadas foram confirmadas pelas defasagens comunicativas e de aprendizagem encontradas na observação clínica.

Verificou-se que a maioria das crianças com dificuldades na resolução temporal (indivíduos 1, 2, 3, 4, 6, 7, 8, 10, 11, 12, 13, 14, 16, 17, 18, 20, 22) também apresentaram dificuldades na leitura e na escrita, confirmando os estudos de Rosen (2003), Sharma et al (2009). Ramus et al (2003) que concluíram que uma porcentagem de crianças com problemas de leitura tinha dificuldades nas tarefas do processamento auditivo, concordando com os resultados desta pesquisa.

Os estudos de Benasich et al (2002), McArthur e Bishop (2004a, 2004b), Tallal e Stark (1981), Wible et al (2005), Sharma et al (2009) verificaram coexistência de dificuldade de linguagem e do processamento auditivo em crianças sem FLP. Esta coexistência também pôde ser observada nas crianças com FLP avaliadas nesta pesquisa. Entretanto, as crianças com normalidade na linguagem oral também apresentaram dificuldades nas habilidades do processamento auditivo e atenção auditiva avaliadas. Bishop et al (1999), Rosen (1999) não encontraram dificuldades específicas nas tarefas do processamento auditivo em crianças com distúrbio específico de linguagem.

Do ponto de vista neuropsicológico é fundamental compreender os mecanismos atencionais, na medida em que representam a base de todos os processos cognitivos (Lima 2005). As desordens do processamento auditivo podem trazer como conseqüência sérios prejuízos na comunicação, aprendizagem e no desenvolvimento social (Pereira 1997), mas a plasticidade do sistema nervoso central oferece oportunidades para otimizar as habilidades do processamento 
auditivo (Musiek et al 1991) por meio de estimulação adequada.

Falhas na codificação neural da informação auditiva podem interferir nas habilidades de linguagem, provavelmente, em função da alteração na percepção de pistas acústicas importantes da fala, confirmando a estreita relação entre processamento auditivo e linguagem. Desta forma, para que o processamento lingüístico ocorra adequadamente, torna-se necessário a integridade das habilidades auditivas, assim a fala será codificada, decodificada e integrada, permitindo o reconhecimento de padrões fonológicos da linguagem oral (Feniman e Rissato 2008). Evidenciando, portanto, a importância da estimulação por parte dos pais principalmente nas fases iniciais do desenvolvimento.

Foi possível relacionar o bom desempenho da linguagem oral e a postura estimuladora dos pais durante a avaliação, em alguns casos, sugerindo que a estimulação adequada do meio deve ter tido importância fundamental nos indivíduos com normalidade na linguagem oral. Speltz et al (2000) também afirmaram que a qualidade da interação materna influenciou o índice de desenvolvimento mental em crianças com fissura de lábio e palato e somente palato avaliadas em seu estudo, confirmando os dados desta pesquisa.

Bernaldo e Silva (1998) e Peres (2000) afirmaram que a baixa condição socioeconômica pode sugerir elevado grau de morbidade, internações múltiplas, carência de estímulos positivos do meio, tendo conseqüências no desenvolvimento e crescimento adequados desta população. No presente estudo a maior parte das crianças perteciam ao nível socioeconômico baixo, apenas duas crianças pertenciam ao nível socioeconômico médio inferior; nenhuma criança da pesquisa pertencia aos níveis médio superior, médio ou alto, entretanto, verificou-se bom desempenho cognitivo-lingüístico. Stevens et al (2009) encontraram déficits atencionais em crianças de baixo nível socioeconômico, cujas mães tinham baixo nível de escolaridade. Nesta pesquisa a maioria dos pais, mesmo pertencendo a níveis socioeconômicos mais baixos, mostrou-se interessada no 
desenvolvimento de seus filhos.

As crianças iniciam a aquisição das habilidades auditivas ainda intra-útero e as desenvolvem principalmente nos primeiros anos, necessitando assim, estar expostas a um ambiente com uma variedade de estímulos auditivos, simples e complexos (Feniman e Rissato 2008), os quais favorecerão adquirir linguagem e desenvolver sua fala.

De forma geral, os pais mostraram estar atentos quanto ao desenvolvimento de seus filhos, pois das dez crianças cujos pais não referiram queixas de linguagem e aprendizagem, apenas uma apresentou dificuldades nestas áreas (indivíduo 20); notou-se que esta mãe também apresentava dificuldades de compreensão e expressão oral. Quanto aos pais que referiram queixas, estas foram confirmadas pelas avaliações realizadas.

Com relação à produção articulatória da fala observou-se alta freqüência de DACs e distúrbios dento-oclusais (DDO) (92\%), os quais prejudicavam a inteligibilidade de fala nestas crianças, lembrando-se que todas tinham sido submetidas à reconstrução cirúrgica do palato. Tais achados são divergentes dos de Hall e Golding-Kushner (1989), com dados de $80 \%$ de fala normal após cirurgia corretora do palato antes de 18 meses de idade. Apenas duas crianças do presente estudo não apresentaram dificuldades com relação à articulação. A maioria dos indivíduos (66\%) apresentou DDO, 13\% apresentaram DACs e outros 13\% apresentaram DACs e DDOs.

Pamplona et al (2000a) afirmam que os DACs podem ocorrer inicialmente pela presença de fissura palatina, produzindo um transtorno fonético e com o tempo estes erros podem ser incorporados ao sistema de regras da linguagem, produzindo um transtorno fonológico. Desta forma, chamam atenção para a relação existente entre a presença de articulação compensatória e o nível de desenvolvimento lingüístico nestas crianças, o que não pôde ser confirmado neste estudo, já que não houve maior freqüência de dificuldades na linguagem oral nas crianças com 
DACs, quando comparadas às crianças sem DACs.

Como parte do estudo as crianças passavam por avaliação psicológica, entretanto, os resultados eram disponibilizados à avaliadora após a finalização da pesquisa, desta forma, não houve influência do desempenho intelectual sobre a avaliação lingüística. Com relação ao desempenho cognitivo estudos sugerem déficit na capacidade intelectual em crianças com FLP (Jocelyn et al 1996, Speltz et al 2000, Pegoraro-Krook et al 2004), discordando dos resultados desta pesquisa, em que somente dois indivíduos (indivíduos 13 e 20) foram classificados como definidamente abaixo da média na capacidade intelectual, sendo que nenhum indivíduo foi excluído por apresentar deficiência intelectual. Os indivíduos classificados como definidamente abaixo da média na capacidade intelectual apresentaram dificuldades em todas as habilidades da linguagem oral, receptiva e expressiva, bem como do processamento auditivo e atenção auditiva, confirmando a integração entre cognição, linguagem e processamento auditivo.

Na tabela 15 estão apresentadas as correlações encontradas entre a avaliação cognitiva e os demais instrumentos de avaliação lingüística (TVIP, PHF, subtestes de associação auditiva, closura gramatical e visual, memória auditiva do ITPA), sugerindo que indivíduos com déficit no desempenho intelectual podem apresentar dificuldades no vocabulário receptivo, nas habilidades fonológicas, associação auditiva, memória auditiva, closura visual e sintaxe.

Schönweiler et al $(1998,1999)$, demonstraram que a função auditiva teve maior influência no desempenho da fala e linguagem, superando os efeitos da fissura por si mesma independentemente da forma e extensão. Tais achados reforçam a necessidade do acompanhamento periódico e que além do enfoque na fala, estas crianças devem ser acompanhadas quanto à aquisição e desenvolvimento da linguagem, preferencialmente por equipe multidisciplinar (Musolino e Rodrigues 1994, Schönweiler et al 1998) possibilitando maiores esclarecimentos quanto ao caso. 
Entretanto, esta equipe necessita ter uma visão integral do ser, substituindo a visão em partes para promover o que atualmente considera-se saúde, de acordo com a nova definição da Organização Mundial de Saúde: "não somente a ausência de doença, mas principalmente, o bemestar físico, psíquico e social"; recentemente ampliada para incluir o bem estar espiritual, sendo também por muitos defendida a inclusão da visão de "bem-estar" em um meio ambiente equilibrado e sustentável (Crema 2003).

Desta forma, o profissional da área da saúde deve estar convenientemente preparado para trabalhar todas as dimensões existenciais do ser humano e da vida humana. Assim, ampliando as possibilidades de desenvolvimento das habilidades comunicativas, lingüísticas, de aprendizado, de crescimento e desenvolvimento do indivíduo, levando em conta suas particularidades. Rosenthal e Jacobson (1966) verificaram em seus estudos que as crianças tornavam-se a medida da expectativa de seus professores, alertando sobre a importante influência que o educador exerce sobre as crianças e a necessidade de ampliar o olhar e enxergar o ser, evitando rotulá-lo ou prendê-lo.

Sabe-se que o desenvolvimento da linguagem é individual, depende de diferentes fatores, tais como adequação do sistema nervoso central, estimulação recebida do meio, vínculo mãefilho, capacidade intelectual, nível socioeconômico, etc, devendo-se, portanto, considerar cada criança de forma única, respeitando sua individualidade e o meio em que se insere. Os dados deste estudo sugerem a importância da avaliação das habilidades de linguagem de forma que possam ser desenvolvidas abordagens de orientação aos pais quanto ao desenvolvimento destas habilidades em crianças com FLP, visando otimizar o desenvolvimento da linguagem oral e escrita nesta população.

Os resultados obtidos até o momento devem ser considerados preliminares, necessitandose ampliar a casuística, a faixa etária, o nível socioeconômico e a questão das intervenções 
fonoaudiológicas. No entanto, os dados alcançados podem ser úteis na eleição tanto de dificuldades quanto de habilidades, possibilitando a seleção de diferentes abordagens terapêuticas em crianças com FLP da mesma faixa etária, além de importantes implicações para o tratamento desta população. 


\section{CONCLUSÃO.}

Com base nos achados das habilidades de linguagem de crianças com FLP, entre 7 e 9 anos de idade, analisadas neste estudo, pode-se concluir que o desempenho lingüístico estava aquém do esperado para a idade na maioria dos indivíduos com FLP. As habilidades mais prejudicadas foram a escrita, associação auditiva, linguagem receptiva, associação visual, leitura e aritmética. As habilidades do processamento e atenção auditiva analisadas estavam defasadas em quase todos os indivíduos avaliados. 


\section{REFERÊNCIAS.}

Santana AMM, Acosta VM. La evaluación Del lenguage: teoria y prática Del proceso de evaluación en la conducta lingüistica infantil. Archidona: Ajibe, 1996.

Agresti A. Categorical Data Analysis. New York: Wiley. 1990.

Aguado G. TSA - El desarrollo de la morfosintaxis en el niño. Madrid: CEPE, 1989.

Altmann EBC. Fissuras lábio palatinas. 4ª ed. Carapicuíba: Pró-Fono; 1997.

American Speech-Language-Hearing Association. Roles and responsibilities of speech-language pathologists with respect to reading and writing in children and adolescents (guidelines). Rockville. MD: Author. 2001.

American Speech-Language-Hearing Association Working Group on Auditory Processing Disorders. Central auditory processing. www.asha.org/members/deskref-journals/deskref/default. Visitado em 04/08/2005.

Anastasi A. Testes psicológicos. São Paulo: Herder, Universidade de São Paulo.1967.

Andrade, C.R.F. de; Befi-Lopes, D.M.; Fernandes, F.D.M.; Wertzner, H.F. ABFW. Teste de Linguagem Infantil nas áreas de fonologia, vocabulário, fluência e pragmática. Carapicuíba: 
Pró-Fono, 2001.

Benasich AA, Thomas JJ, Leppanen PHT. The importance of rapid auditory processing abilities to early language development: Evidence of converging methodologies. Dev Psychobiol 2002; 40: 278-92.

Bernaldo AJN, Silva IS. Alimentação do recém-nascido. In: Basseto MCA, Brock R, Wajnsztejn R. Neonatologia um convite à atuação fonoaudiológica. São Paulo: Lovise, 1998. p.75-84.

Bishop DVM, Carlyton RP, Deeks JM, Bishop SJ. Auditory temporal processing impairment: Neither necessary nor sufficient for causing language impairment in children. J Speech Lang Hear Res 1999; 42: 1295-310.

Bogossian MADS. Estudo preliminar sobre a bateria I.T.P.A. Illinois Test of Psycholinguistic Abilities [dissertação], Rio de Janeiro: Pontifícia Universidade Católica; 1975.

Bogossian MADS, Santos MJ. Manual do examinador: Teste Illinois de Habilidades Psicolingüisticas. Rio de Janeiro: EMPSI; 1977.

Boscariol M, André KD, Feniman MR. Crianças com fissura isolada de palato: desempenho nos testes de processamento auditivo. Rev. Bras. Otorrinolaringol [online] 2009; 75: 213-20.

Broder HL, Richman LC, Matheson PB. Learning disability, school achievement, and grade retention among children with cleft: a two-center study. Cleft Palate Craniofac J 1998; 35:127- 
31.

Broen PA, Moller KT, Carlstrom J, Doyle SS, Devers M, Keenan KM. Comparison of the hearing histories of children with and without cleft palate. Cleft Palate Craniofac J 1996; 33: $127-33$.

Bzoch KR. Communicative disorders related to cleft lip and palate. Boston: College-Hill Press; 2004.

Bzoch KR, Kemker FJ, Dixon-Wood VL. The prevention of communicative disorders in cleft palate infants. In: Lass N, editor. Speech and language: advances in basic research and practice. New York: Academic Press. $9^{\text {a }}$ ed. 1984.

Carvalho IA, Alvarez AMMA, Caetano AL. Perfil de Habilidades Fonológicas. São Paulo: Via Lettera, 1998.

Chapman KL, Graham K, Gooch J, Visconti C. Conversational skills of preschool and school-age children with cleft lip and palate. Cleft Palate Craniofac J 1998; 35:503-16.

Chiari BM, Basilio CS, Nakagawa EA, Cormedi MA, Silva NSM, Cardoso RM, Parreira VEW. Proposta de sistematização de dados da avaliação fonoaudiológica através da observação de comportamentos de criança de 0 a 6 anos. Pró-Fono Rev Atual Cient 1991; 3:29-36.

Crema R. Strasbourg, França, Transdisciplinarité, Science de la Paix. In: 3èmes Rencontres 
Internationales, Science \& Conscience, 16 mai. 2003. [Informação verbal].

Crystal D. Lenguaje infantil, aprendizaje y lingüistica. Barcelona: Médica \& Técnica. 1981.

Davis H, Silverman RS. Hearing and Deafness. New York: Holt, 1970.

De Renzi E, Faglioni P. Normative data and screening power of a shortened version of the Token test. Córtex 1978; 14: 41-9.

De Renzi E, Vignolo LA. The Token test: a sensitive test to detect receptive disturbances in aphasics. Brain 1962; 85:665-78.

Dixon-Wood VL. Counseling and early management of feeding and language skill development for infants and toddlers with cleft palate. In: Bzoch KR. Communicative disorders related to cleft lip and palate. Austin: Pro-Ed; $5^{\mathrm{a}}$ ed. 2004. p.669-82.

Dunn LM, Padilla ER, Lugo DE, Dunn LM. Peabody Picture Vocabulary Test - revised. Circle Pines, MN: American Guidance Service, 1986.

Eliason MJ, Richman LC. Language development in preschoolers with cleft. Dev Neuropsychol $1990 ; 6: 173-82$.

Feagans L, Sanyal M, Henderson F, Collier A, Appelbaum M. Relationship of middle ear disease in early childhood to later narrative and attentional skills. J Pediatr Psychol 1987;12:581-94. 
Félix TM, Spritzer D, Bauermann CB, Gerhardt KD, Collares MV. Estudo genético clínico de pacientes com fissura lábio palatina no Hospital das Clínicas de Porto Alegre. In: $14^{\circ}$ Congresso Brasileiro de Genética Clínica; Ribeirão Preto; 2002.

Feniman MR. Aplicação do teste de atenção auditiva FC2 em crianças ouvintes normais [livredocência], Bauru: Faculdade de Odontologia de Bauru, Universidade de São Paulo; 2004.

Feniman MR, Rissato ACS. Processamento auditivo e estratégias terapêuticas comportamentais para o transtorno do processamento auditivo. In: Lamônica DAC. Estimulação da linguagem aspectos teóricos e práticos. São José dos Campos: Pulso; 2008.

Fletcher P, MacWhinney B. Compêndio da Linguagem da Criança. Porto Alegre: Artes Médicas. 1997.

Friel-Patti S, Finitzo T. Language learning in a prospective study of otitis media with effusion in the first two years of life. J Speech Lang Hear Res 1990; 33:188-194.

Genaro KF, Yamashita RP, Trindade IEK. Avaliação clínica e instrumental na fissura labiopalatina. In: Ferreira LP, Befi-Lopes DM, Limonge SCO (Org.). Tratado de Fonoaudiologia. São Paulo: Roca; 2004. p.456-93.

Giacheti CM. Displasia Fronto-Nasal: achados da linguagem oral em individuos com e sem anomalias estruturais do corpo caloso [tese], São Paulo: Escola Paulista de Medicina, Universidade Federal de São Paulo; 1996. 
Golding-Kushner KJ. Therapy techniques for cleft palate speech \& related disorders. San Diego: Singular; 2001.

Goldsberry G, O'Leary D, Hichwa R, Nopoulos P. Functional abnormalities in the neural circuitry of reading in men with nonsyndromic clefts of the lip or palate. Cleft Palate Craniofac $J$ 2006; 43:683-90.

Gomes PRM, Mélega JM. Tratamento cirúrgico In: Altmann EBC. Fissuras Lábio Palatinas. São Paulo: Pró-Fono; 1997. p.61-72.

Graciano MIG, Lehfeld NAS, Neves Filho A. Critérios de avaliação para classificação sócioeconômica: elementos de atualização - Parte II. Serv Soc Real 1996; 5:171-201.

Grunwell P, Sell DA. Fala e fenda palatina - anomalias velofaríngeas. In: Grunwell P, Sell DA, Watson RE. Tratamento da fissura labial e fenda palatina. São Paulo: Livraria Santos Editora. 2005. pg 68-86.

Hall C, Golding-Kushner KJ. Long-term follow-up of 500 patients after palate repair performed prior to 18 months of age. Paper presented at Sixth International Congress on Cleft Palate and Related Craniofacial Anomalies, Jerusalem, Israel. 1989.

Igawa HH, Nishizawa N, Sugi H, Inuyama Y. A fibercopic analysis of velopharyngeal movement before and after primary palatoplasty in cleft palate infants. Plast Reconstr Surg 1998; 102:66874. 
Jerger J. Clinical experience with impedance audiometry. Arch Otolaryngol 1970; 92:311-24.

Jocelyn LJ, Penko MA, Rode HL. Cognition, communication, and hearing in young children with cleft lip and palate and in control children: a longitudinal study. Pediatrics 1996; 97:529-34.

Keith RW. Random gap detection test. Missouri: Auditec of Saint Louis, 2000.

Kirk SA, McCarthy JJ. The Illinois Test of Psycholinguistic Abilities: an approach to differential diagnosis. Am J Ment Defic 1961; 66:399-412.

Kirk SA, McCarthy JJ, Kirk WD. The Illinois Test of Psycholinguistic Abilities. Urbana: University of Illinois 1968.

Konst EM, Rietveld T, Peters HFM, Kuijpers-Jagtman AM. Language skills of young children with unilateral cleft lip and palate following infant orthopedics: a randomized clinical trial. Cleft Palate Craniof J 2003; 40: 356-362.

Lamprecht RR. Aquisição fonológica do Português. Porto Alegre: Editora Artmed. 2004.

Lemos ICC, Monteiro CZ, Camrago RA, Rissato ACS, Feniman MR. Teste Dicótico de Dígitos (etapa de escuta direcionada) em crianças com fissura labiopalatina. Rev Bras Otorrinolaringol 2008; 74: 662-7.

Lima RF. Compreendendo os mecanismos atencionais. Cien Cogn 2005; 6:113-22. 
Lowe RJ. Fonologia: avaliação e intervenção - aplicações na patologia da fala. Porto Alegre: Artes Médicas; 1996.

Marcelino FC, Hamer BL. Intervenção fonoaudiológica em crianças com atraso de linguagem: uma visão integral. In: Lopes-Herrera AS, Maximino LP. Intervenção Fonoaudiológica nas Alterações da Linguagem Oral Infantil. (no prelo).

McArthur GM, Bishop DVM. Frequency discrimination deficits in people with specific language impairment: Reliability, validity, and linguistics correlates. J Speech Lang Hear Res 2004a; 47: $527-41$.

McArthur GM, Bishop DVM. Which people with specific language impairment have auditory processing deficits? Cogn Neuropsychol 2004b; 21: 79-94.

McWilliams BJ, Morris HL, Shelton RL. Cleft Palate Speech. 2nd edn. Philadelphia: BC Decker; 1990.

Melgaço CA, Di Ninno CQMS, Penna LM, Vale MPP. Aspectos ortodôndicos/ortopédicos e fonoaudiológicos relacionados a pacientes portadores de fissuras labiopalatinas. Jornal Brasileiro Ortodôntico Ortopédico Facial 2002; 7:23-32.

Minervino-Pereira ACM. Auto-conceito e auto-estima em indivíduos com fissura labiopalatina: influência do tipo de fissura e do tempo de convivência com a mesma. [dissertação]. Bauru: Hospital de Reabilitação de Anomalias Craniofaciais, Universidade de São Paulo; 2000. 
Moore IJ, Moore GF, Yankers AJ. Otitits media in the cleft palate patient. Ear Nose Throat, 1986; 65:291-295. apud Pegoraro-Krook MI. Efeito da descongestão nasal e do ato de assoar o nariz nas medidas de nasalância [tese de livre docência]. Bauru: Faculdade de Odontologia de Bauru, Universidade de São Paulo; 2004.

Morris H, Ozanne A. Phonetic, phonological, and language skills of children with a cleft palate. Cleft Palate Craniof J 2003; 40: 460-70.

Murray JC. Face facts: genes, environment and cleft. Am J Hum Genetics 1995; 57:227-32.

Musiek FE, Lenz S, Gollegly KM. Neuroaudiologic correlates to anatomical changes of the brain. Am J Audiol 1991; 1:19-24.

Musolino, C.V., Rodrigues, A.P. Equipe clínica: uma reflexão sobre multidisciplinaridade e interdisciplinaridade. In: Marchesan, I.Q., et al (org.). Tópicos em Fonoaudiologia. São Paulo, Lovise, 1995. p. 207-210.

Neiman GS, Savage HE. Development of infants and toddlers with clefts from birth to three years. Cleft Palate Craniofac J 1997; 34:218-225.

Neter J, Kutner MH, Wasserman W, Nachtsheim CJ. Applied Linear Statistical Models. 4ed. McGraw-Hill/Irwin: New York. 1996.

Nguyen PN, Sullivan PK. Issues and controversies in the management of cleft palate. Clin Plast 
Surg 1993; 20:671-82.

Nunn DR, Derkay CS, Darrow DH, Magrew W, Stranick B. The effect of very early cleft palate closure on the need for ventilation tubes in the first year of life. Laryngoscope 1995;9:905-8.

O'Gara MM, Logemann JL. Phonetic analysis of the speech development of babies with cleft palate. Cleft Palate Journal 1988;25:122-34.

Ortiz KZ, Pereira LD. Não-Verbal de Escuta Direcionada. In: Pereira LD, Schochat E. Processamento Auditivo Central - Manual de Avaliação. São Paulo: Lovise, 1997. p.49-60.

Osgood CE. A behavioristic analysis of perception and language as cognitive phenomena: contemporary approaches to cognition. Cambridge: Harvard University, 1957. p.75-118.

Pamplona MC, Ysunza A, González M, Ramírez E, Patiño C. Linguistic development in cleft palate patients with and without compensatory articulation disorder. International Journal of pediatric otorhinolaryngology 2000a; 54:81-91.

Pamplona MC, Ysunza A, Espinoza J. Terapia de lenguage em niños com transtorno de articulacion compensatória. resultados preliminares. Na ORL Mex 2000b; 45:158-62.

Pegoraro-Krook MI, Dutka-Souza JC, Magalhães LCT, Feniman MR. Intervenção fonoaudiológica na fissura palatina. Ferreira LP, Befi-Lopes DM, Limonge SCO (Org.). Tratado de Fonoaudiologia. São Paulo: Roca; 2004. 
Pereira LD. Processamento auditivo central - abordagem passo a passo. In: Pereira LD, Schochat E. Processamento Auditivo Central - Manual de Avaliação. São Paulo: Lovise, 1997. p.49-60.

Peres SPBA. Importância da intervenção dietética no estado nutricional de crianças portadoras de Seqüência de Robin [tese], Botucatu: Faculdade de Medicina de Botucatu, Universidade Estadual Paulista; 2000.

Pérez C. Evaluación del lenguaje oral en la etapa 0-6 años. Madrid: Siglo Veintiuno, 1995.

Perissinoto J. Psicose e neurose: estudo quantitativo do desenvolvimento motor e de linguagem [tese], São Paulo: Escola Paulista de Medicina, Universidade Federal de São Paulo; 1992.

Philips BJ. Early speech management. In: Bardach J, Morris HL, editores. Multidisciplinary management of cleft lip and palate. PA: W.B. Saunders Company; 1990. p.750-7.

Ramus F, Rosen S, Dakin SC, Day BL, Castellote JM, White S, Frith U. Theories of developmental dyslexia: insights from a multiple case study of dyslexic adults. Brain 2003; 126 : $841-65$

Raven JC, Court JH, Raven J. General overview. Oxford: Oxford Psychologists Press, 1998.

Richman LC, Eliason MJ. Type of reading disability related to cleft type and neuropsychological patterns. Cleft Palate J 1984; 21:1-6. 
Richman LC, Eliason MJ. Disorders of communication: Developmental language disorders and cleft palate. In Walker E, Roberts M (ed). Handbook of clinical child psychology. New York: Wiley; 1995. p. 537-52.

Richman LC, Wilgenbusch T, Hall T. Spontaneous verbal labeling: visual memory and reading ability in children with cleft. Cleft Palate Craniof J 2005; 42: 565-69.

Roberts JE, Burchinal MR, Medley L, Zeisel SA, Mundy M, Roush J, et al. Otitis media, hearing sensitivity, and maternal responsiveness in relation to language during infancy. J Pediatr 1995; 126: 481-89.

Rosen S. A problem with auditory processing? Current Biology 1999; 9: 698-700.

Rosen S. Auditory processing in dyslexia and specific language impairment: Is there a deficit? What is its nature? Does it explain anything? J Phon 2003; 31: 509-27.

Rosenthal R, Jacobson L. Teachers' expectancies: Determinates of pupils' IQ gains. Psychological Reports 1966. 19:115-18.

Santos, MJ. Adaptacão e avaliação de três subtestes do Illinois Test of Psycholinguistic Abilities [dissertação], Rio de Janeiro: Pontifícia Universidade Católica, 1977.

Santos MFC, Pereira LD. Escuta com dígitos. In: Pereira LD, Schochat E. Processamento Auditivo Central - Manual de Avaliação. São Paulo: Lovise, 1997. p.147-149. 
Sharma M, Purdy SC, Kelly AS. Comorbidity of Auditory Processing, Language, and Reading Disorders. J Speech Lang Hear Res 2009; 52: 706-22.

Sharp HM, Dailey S, Moon JB. Speech and language development disorders in infants and children with cleft lip and palate. Pediatric Annals 2003: 476-80.

Scherer N, D'Antonio L. Longitudinallanguage development in 20-30 month children with cleft lip and/or palate. Paper presented at the annual convention of the American Speech-LanguageHearing Association, Orlando, FL. 1995.

Shriberg LD, Friel-Patti S, Flipsen P, Brown RL. Otitis media, fluctuant hearing loss, and speechlanguage outcomes: a preliminary structural equation model. J Speech Lang Hear Res 2000; 43:100-20.

Schönweiler R, Radü HJ, Ptok M. A cross-sectional study on speech and language outcome of children having normal hearing, mild fluctuation conductive hearing loss of bilateral profound hearing loss. Int J Pediatr Otorhinolaryngol 1998; 44: 251-8.

Schönweiler R, Lisson AJ, Schönweiler B, Eckardt A, Ptok M, Tränkmann J et al. A retrospective study of hearing, speech and language functions in children with clefts following palatoplasty and veloplasty procedures at 18-24 months of age. Int J Pediatr Otorhinolaryngol 1999; 50:205-17.

Silva Filho OG, Ferrari Junior FM, Rocha DL, Freitas JAS. Classificação das fissuras lábio- 
palatais: breve histórico, considerações clínicas e sugestão de modificação. Ver Bras Cir 1992; 82:59-66.

Snyder LE, Scherer N. The Development of Symbolic Play and Language in Toddlers With Cleft Palate. Am J Speech Lang Pathol 2004; 13: 66-80.

Speltz ML, Endriga MC, Hill S, Maris CL, Jones K, Omnell ML. Cognitive and psychomotor development of infants with orofacial clefts. J Pediatr Psychol 2000; 25:185-90.

Spina V, Psillaks JM, Ferreira MC. Classificação das fissuras lábio-palatinas: sugestão de modificação. Rev Hosp Clin F Méd São Paulo 1972; 27:5-6.

Stein LM. TDE - teste de desempenho escolar: manual para aplicação e interpretação. São Paulo: Casa do Psicólogo, 1994, 60p.

Stengelhofen J. Cleft Palate : the nature and remediation of communication problems. Edinburgh: Churchill Livingstone. 1989.

Stevens C, Lauinger B, Neville H. Differences in the neural mechanisms of selective attention in children from different socioeconomic backgrounds: an event-related brain potential study. Dev Sci 2009; 12:634-46.

Tallal P, Stark RE. Speech acoustic-cue discrimination abilities of normally developing and language impaired children. J Acoust Soc Am 1981; 69: 568-74. 
Tolarová MM, Cervenka J. Classification and birth prevalence of orofacial clefts. Am J Med Genet 1998; 75:126-37.

Trindade IEK, Trindade Júnior AS. Avaliação funcional da inadequação velofaríngea. In: Carreirao S, Lessa S, Zanini AS. Tratamento das fissuras palatinas. $2^{\mathrm{a}}$ ed. Rio de Janeiro: Revinter; 1996. p.223-35.

Wible B, Nicol T, Kraus N. Correlation between brainstem and cortical auditory processes in normal and language-impaired children. Brain 2005; 128: 417-23.

Wyatt R, Sell D, Russell A, Harland K, Albery E. Cleft palate speech dissected: a review of current knowledge and analysis. British Journal of Plastic Surgery 1996; 49:143-9.

Williams WN, Seagle B, Nackashi J, Marks R, Boggs SR, Kemker J, Wharton W, et al. A methodology report of a randomized prospective clinical trial to assess velopharyngeal function for speech following palatal surgery. Controlled Clinical Trials 1998; 19:297-312.

Yavas M, Hernandorena CLM, Lamprecht RR. Avaliação Fonológica da Criança - reeducação e terapia. Porto Alegre: Artes Médicas. 1992.

\section{BIBLIOGRAFIA CONSULTADA}

Grigolli AG. Metodologia do trabalho científico e recursos informacionais na área da saúde. São Paulo: Editora Santos, 2008, 208p. 
Universidade de São Paulo. Hospital de Reabilitação de Anomalias Craniofaciais. Guia para elaboração de dissertações e teses. Curso Pós-Graduação - HRAC. Bauru: Hospital de Reabilitação de Anomalias Craniofaciais; 2004.

Da Cás D. Manual teórico-prático para elaboração metodológica de trabalhos acadêmicos. São Paulo: Jubela Livros, 2008, 236p. 


\section{Anexo 1 - Ofício de aprovação do projeto emitido pelo Comitê de Ética em Pesquisa em}

\section{Seres Humanos.}

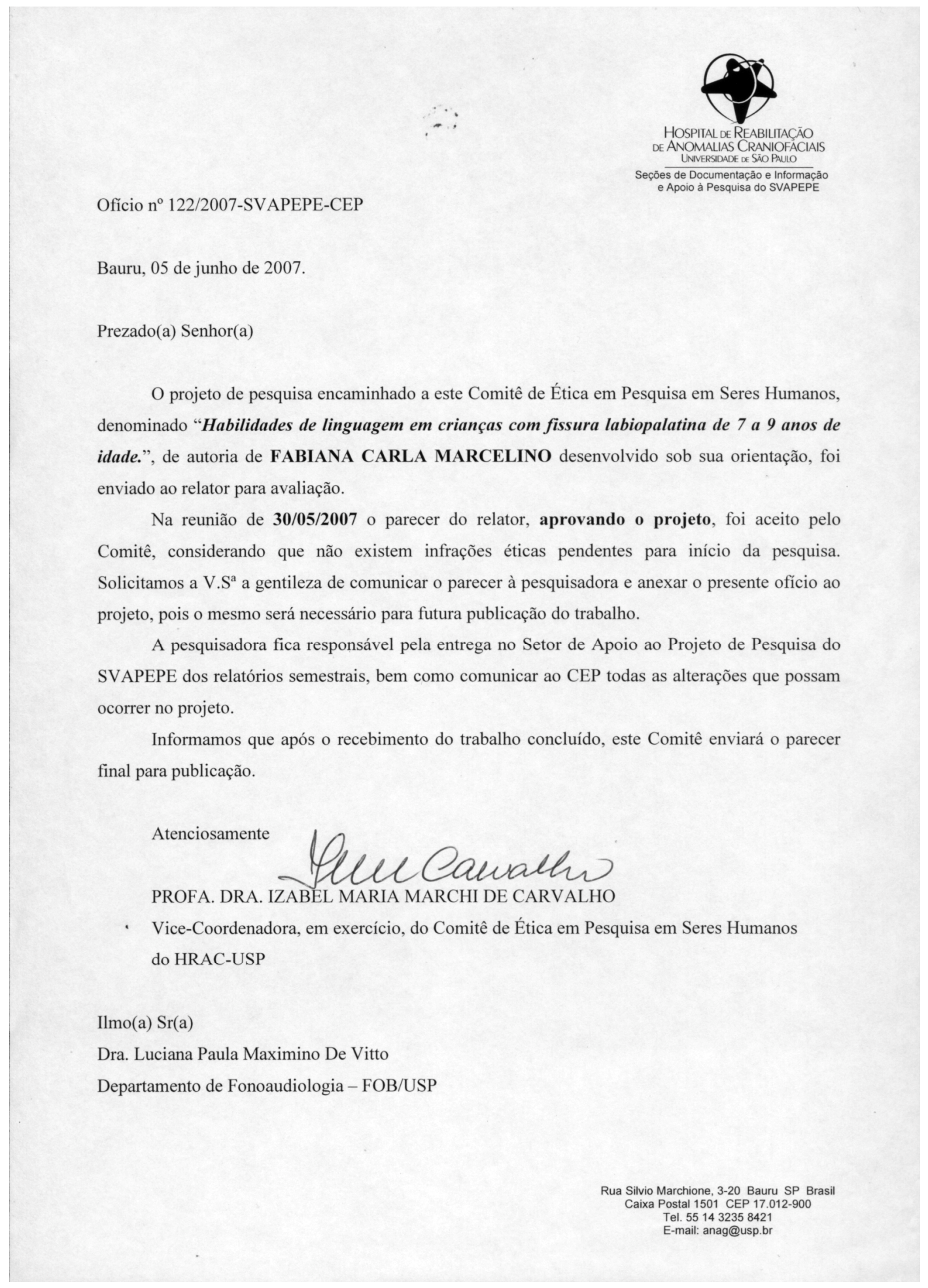




\section{Anexo 2 - Termo de consentimento livre e esclarecido.}

Pelo presente instrumento que atende às exigências legais, o Sr.(a) , portador da cédula de identidade

responsável pelo paciente , após leitura minuciosa deste documento, devidamente explicado pelos profissionais em seus mínimos detalhes, ciente dos serviços e procedimentos aos quais será submetido, não restando quaisquer dúvidas a respeito do lido e explicado, firma seu CONSENTIMENTO LIVRE E ESCLARECIDO concordando em participar da pesquisa Habilidades de linguagem em crianças com fissura labiopalatina de 7 a 9 anos de idade, realizada por Fabiana Carla Marcelino, CRFa 11021, sob orientação da Profa. Dra. Luciana Paula Maximino De Vitto, CRFa 7238 que tem como objetivo caracterizar as habilidades de linguagem oral em crianças com fissura labiopalatina e será realizada avaliação: fonoaudiológica, do processamento auditivo e cognitiva. Estas atividades serão realizadas em um período de três horas.

A avaliação fonoaudiológica englobará as habilidades comunicativas da linguagem oral e audição.

Em relação às habilidades comunicativas serão caracterizados os comportamentos relativos à utilização da comunicação, por meio da habilidade do indivíduo responder às questões solicitadas, iniciar, manter e participar da atividade. Situações de fala encadeada e dirigida serão as estratégias básicas para a avaliação dos recursos utilizados na comunicação destes indivíduos.

Os testes a seguir serão utilizados como complementação dos achados da observação clínica.

- Teste Illinois de Habilidades Psicolingüísticas (ITPA): avalia habilidades relacionadas ao processo de comunicação: memória visual e auditiva, associação visual e auditiva (relacionar conceitos), closura visual e gramatical (reconhecer o todo através das partes).

- Teste de Vocabulário Por Imagens Peabody (TVIP): avalia o vocabulário da criança por meio de figuras. A criança deverá apontar a figura relacionada com o estímulo verbal.

- Perfil das habilidades fonológicas (PHF): avalia a capacidade do indivíduo em processar os sons da língua, tais como rima, substituição, adição, segmentação de sílabas e sons, etc.

- Teste Token: avalia as habilidades da linguagem receptiva. O teste é composto por 20 peças: círculos e quadrados, grandes e pequenos, de 4 cores (preto, vermelho, amarelo e branco). As atividades apresentam um aumento sucessivo de dificuldade.

- Teste do Desempenho Escolar (TDE): avalia as capacidades fundamentais para o desempenho escolar, mais especificamente da escrita, aritmética e leitura. Este teste será realizado apenas nas crianças alfabetizadas.

A avaliação do Processamento Auditivo é um procedimento para diagnosticar o uso funcional correto e eficiente da audição, importante para a criança se comunicar adequadamente, para o aprendizado escolar e todas as atividades que englobam a audição e linguagem. Serão avaliados:

- Processamento Temporal: a habilidade avaliada é o reconhecimento da ordenação de estímulos sonoros.

- Teste Dicótico de Dígitos: avalia a habilidade para agrupar e identificar estímulos sonoros no meio de ruído e avalia a comunicação entre os dois hemisférios cerebrais. 
- Teste Dicótico Não Verbal: avalia a habilidade de atenção seletiva. O sujeito deve prestar atenção em um som, ignorando o som apresentado na orelha oposta e apontar a figura correspondente.

- Teste da Habilidade de Atenção Auditiva Sustentada: palavras monossilábicas são apresentadas à criança, a qual deverá levantar a mão apenas para uma palavra alvo. Avalia a habilidade de atenção sustentada e vigilância auditiva.

A avaliação cognitiva será realizada por psicólogo, objetivando caracterizar a inteligência geral.

Caso haja o consentimento do responsável, a avaliação fonoaudiológica poderá ser filmada.

Os pacientes receberão em sua casa um relatório conclusivo sobre as avaliações realizadas, enviado por correio pelo pesquisador.

Importante esclarecer que esta pesquisa é independente da participação do paciente no Projeto Flórida.

Caso o sujeito da pesquisa queira apresentar reclamações em relação a sua participação na pesquisa poderá entrar em contato com o Comitê de Ética em Pesquisa em Seres Humanos, do HRAC-USP, pelo endereço Rua Silvio Marchione, 3-20 na Unidade de Ensino e Pesquisa ou pelo telefone (14)3235-8421.

Fica claro que o sujeito da pesquisa ou seu representante legal, pode a qualquer momento retirar seu CONSENTIMENTO LIVRE E ESCLARECIDO e deixar de participar desta pesquisa e ciente de que todas as informações prestadas tornar-se-ão confidenciais e guardadas por força de sigilo profissional (Art. 13 do Código de Ética da Fonoaudiologia).

Por estarem de acordo assinam o presente termo.

Bauru-SP de de

Assinatura do sujeito da pesquisa ou responsável
Assinatura do pesquisador responsável

Pesquisador responsável: Fabiana Carla Marcelino

R. Aracy Pelegrino Brazoloto 1-16, Bauru, SP, 17030-160, Tel (14) 91125768, fabimarcelino@yahoo.com

Endereço institucional: R. Silvio Marchione, 3-20, Bauru, SP, 17012-900

Tel(14)32358162 ramal 8434 
Anexo 3 - Protocolo de Entrevista.

\section{UNIVERSIDADE DE SÃO PAULO \\ HOSPITAL DE REABILITAÇÃO DE ANOMALIAS CRANIOFACIAIS - USP \\ PROTOCOLO DE ENTREVISTA}

Nome:

Idade Atual: __ a_m DN: $\_$I_L

Informante: Data: ( )Destra ( )Canhota ( )Usa prótese de palato

1) Queixa:

2) HPQ:

3) Antecedentes familiares: Recorrência familial: ( )sim ( )não Consangüinidade ( )sim ( )não

4) Gestação: idade materna: idade paterna:

Pré-Natal: acompanhamento: ( ) sim ( ) não medicamentos: ( ) sim ( ) não

5) Parto:

6) Condicões do RN: Peso:

Choro:
Comprimento:

Cianose: intercorrências: ( ) sim ( ) não drogas: ( ) sim ( ) não

7) Desenvolvimento Global:

ALIMENTAÇÃO: Mamou peito até:

MOTOR: Firmou cabeça:

Engatinhou:

Caía muito:
Utilizou mamadeira até:

Sentou com apoio: $\quad$ Sentou sem apoio:

Andou:
COMUNICAÇÃO: $1^{\text {as }}$ palavras:

dificuldades:

gagueja:

lê:

desempenho escolar:

dificuldades específicas: matemática: audição: otites:

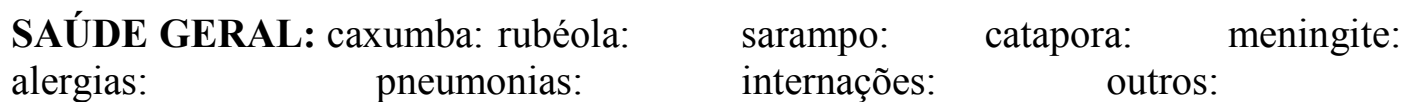

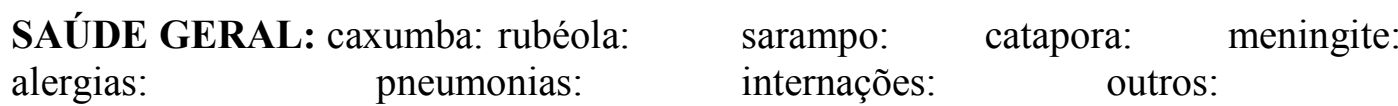

$1^{\text {as }}$ frases:

quais/duração:

troca sons: voz:

escreve: dificuldades:

8) Medicamentos Atuais:

9) Outros Atendimentos:

Fonoaudióloga Responsável: Fabiana C. Marcelino CRFa: 11021 
Anexo 4. Caracterização da amostra segundo a idade, sexo, procedência, nível socioeconômico e escolaridade.

\begin{tabular}{cccccc}
\hline Indivíduo & Idade & Sexo & $\begin{array}{c}\text { Procedência } \\
\text { (estado) }\end{array}$ & $\begin{array}{c}\text { Nível } \\
\text { Socioeconômico }\end{array}$ & $\begin{array}{c}\text { Escolaridade } \\
\text { (série) }\end{array}$ \\
\hline $\mathbf{1}$ & $7 \mathrm{a} 4 \mathrm{~m}$ & $\mathrm{M}$ & $\mathrm{MG}$ & Baixo superior & $1^{\mathrm{a}}$ \\
$\mathbf{2}$ & $7 \mathrm{a} 9 \mathrm{~m}$ & $\mathrm{~F}$ & $\mathrm{SP}$ & Baixo inferior & $2^{\mathrm{a}}$ \\
$\mathbf{3}$ & $8 \mathrm{a} 10 \mathrm{~m}$ & $\mathrm{M}$ & $\mathrm{SP}$ & Baixo superior & $2^{\mathrm{a}}$ \\
$\mathbf{4}$ & $7 \mathrm{a} 4 \mathrm{~m}$ & $\mathrm{M}$ & $\mathrm{RJ}$ & Baixo superior & $1^{\mathrm{a}}$ \\
$\mathbf{5}$ & $9 \mathrm{a} 4 \mathrm{~m}$ & $\mathrm{~F}$ & $\mathrm{MG}$ & Baixo inferior & $3^{\mathrm{a}}$ \\
$\mathbf{6}$ & $8 \mathrm{a} 2 \mathrm{~m}$ & $\mathrm{M}$ & $\mathrm{DF}$ & Baixo inferior & $3^{\mathrm{a}}$ \\
$\mathbf{7}$ & $9 \mathrm{a} 1 \mathrm{~m}$ & $\mathrm{~F}$ & $\mathrm{SP}$ & Baixo superior & $3^{\mathrm{a}}$ \\
$\mathbf{8}$ & $7 \mathrm{a} 10 \mathrm{~m}$ & $\mathrm{~F}$ & $\mathrm{MG}$ & Baixo superior & $1^{\mathrm{a}}$ \\
$\mathbf{9}$ & $7 \mathrm{a} 6 \mathrm{~m}$ & $\mathrm{M}$ & $\mathrm{SC}$ & Médio inferior & $1^{\mathrm{a}}$ \\
$\mathbf{1 0}$ & $9 \mathrm{a} 2 \mathrm{~m}$ & $\mathrm{M}$ & $\mathrm{RJ}$ & Baixo superior & $3^{\mathrm{a}}$ \\
$\mathbf{1 1}$ & $9 \mathrm{a} 2 \mathrm{~m}$ & $\mathrm{~F}$ & $\mathrm{SP}$ & Baixo inferior & $3^{\mathrm{a}}$ \\
$\mathbf{1 2}$ & $9 \mathrm{a} 9 \mathrm{~m}$ & $\mathrm{~F}$ & $\mathrm{SP}$ & Baixo superior & $4^{\mathrm{a}}$ \\
$\mathbf{1 3}$ & $9 \mathrm{a} 4 \mathrm{~m}$ & $\mathrm{~F}$ & $\mathrm{MG}$ & Baixo inferior & $2^{\mathrm{a}}$ \\
$\mathbf{1 4}$ & $7 \mathrm{a} 10 \mathrm{~m}$ & $\mathrm{M}$ & $\mathrm{GO}$ & Baixo inferior & $2^{\mathrm{a}}$ \\
$\mathbf{1 5}$ & $9 \mathrm{a} 8 \mathrm{~m}$ & $\mathrm{~F}$ & $\mathrm{SC}$ & Médio inferior & $4^{\mathrm{a}}$ \\
$\mathbf{1 6}$ & $9 \mathrm{a} 2 \mathrm{~m}$ & $\mathrm{~F}$ & $\mathrm{SP}$ & Baixo superior & $3^{\mathrm{a}}$ \\
$\mathbf{1 7}$ & $8 \mathrm{a} 8 \mathrm{~m}$ & $\mathrm{M}$ & $\mathrm{RS}$ & Baixo superior & $3^{\mathrm{a}}$ \\
$\mathbf{1 8}$ & $7 \mathrm{a} 2 \mathrm{~m}$ & $\mathrm{~F}$ & $\mathrm{MG}$ & Baixo superior & $1^{\mathrm{a}}$ \\
$\mathbf{1 9}$ & $9 \mathrm{a} 6 \mathrm{~m}$ & $\mathrm{M}$ & $\mathrm{SP}$ & Baixo superior & $4^{\mathrm{a}}$ \\
$\mathbf{2 0}$ & $7 \mathrm{a} 5 \mathrm{~m}$ & $\mathrm{~F}$ & $\mathrm{MS}$ & Baixo superior & $2^{\mathrm{a}}$ \\
$\mathbf{2 1}$ & $8 \mathrm{a} 11 \mathrm{~m}$ & $\mathrm{M}$ & $\mathrm{RS}$ & Baixo inferior & $2^{\mathrm{a}}$ \\
$\mathbf{2 2}$ & $8 \mathrm{a} 7 \mathrm{~m}$ & $\mathrm{~F}$ & $\mathrm{SP}$ & Baixo superior & $3^{\mathrm{a}}$ \\
$\mathbf{2 3}$ & $7 \mathrm{a} 6 \mathrm{~m}$ & $\mathrm{M}$ & $\mathrm{MS}$ & Baixo inferior & $2^{\mathrm{a}}$ \\
$\mathbf{2 4}$ & $9 \mathrm{a} 0 \mathrm{~m}$ & $\mathrm{~F}$ & $\mathrm{MG}$ & Baixo inferior & $3^{\mathrm{a}}$ \\
\hline
\end{tabular}

Legenda: MG: Minas Gerais

SC: Santa Catarina
SP: São Paulo

GO: Goiás
RJ: Rio de Janeiro

RS: Rio Grande do Sul
DF: Distrito Federal

MS: Mato Grosso do Sul 
Anexo 5 - Dados sobre queixa fonoaudiológica atual dos pais, período de ocorrência de otites e sua freqüência.

\begin{tabular}{|c|c|c|c|}
\hline Indivíduo & $\begin{array}{c}\text { Queixa fonoaudiológica } \\
\text { atual }\end{array}$ & Otite (período) & $\begin{array}{c}\text { Otite } \\
\text { (freqüência) }\end{array}$ \\
\hline 1 & ausente & $\begin{array}{c}4 \mathrm{x} \text { antes de } 1 \text { ano } \\
\mathrm{e} 1 \mathrm{x} \text { aos } 7 \mathrm{a}\end{array}$ & $2-1-1-1$ \\
\hline 2 & atenção & $1 \mathrm{a}$ & $1 \mathrm{x}$ \\
\hline 3 & atenção e aprendizagem & ausente & - \\
\hline 4 & aprendizagem & $3 m-6 a$ & recorrente \\
\hline 5 & ausente & $8 \mathrm{a}$ & $1 \mathrm{x}$ \\
\hline 6 & atenção, expressão verbal & ausente & - \\
\hline 7 & $\begin{array}{l}\text { atenção, memória, } \\
\text { aprendizagem }\end{array}$ & $6 a$ & $1 \mathrm{x}$ \\
\hline 8 & velocidade de fala & $0-3 a$ & recorrente \\
\hline 9 & trocas na fala & $1 \mathrm{a} 9 \mathrm{~m}$ & $1 \mathrm{x}$ \\
\hline 10 & atenção, aprendizagem & $6 \mathrm{~m}$ & $1 \mathrm{x}$ \\
\hline 11 & lentidão & $8 \mathrm{a}$ & $1 \mathrm{x}$ \\
\hline 12 & ausente & $1 \mathrm{a} 6 \mathrm{~m}-8 \mathrm{a}$ & $5 x$ \\
\hline 13 & atenção & $\begin{array}{c}5 \mathrm{x} \text { antes de } 1 \mathrm{a}, 3 \mathrm{x} \\
\text { antes de } 1 \mathrm{a} 6 \mathrm{~m}\end{array}$ & $8 \mathrm{x}$ \\
\hline 14 & velocidade de fala & $0-3 a$ & $2 \mathrm{x}$ \\
\hline 15 & ausente & ausente & - \\
\hline 16 & ausente & $1-5 a$ & $6 x$ \\
\hline 17 & velocidade de fala & ausente & - \\
\hline 18 & ausente & $2 \mathrm{a} 9 \mathrm{~m}$ e $5 \mathrm{a} 4 \mathrm{~m}$ & $2 \mathrm{x}$ \\
\hline 19 & atenção & $4 a$ & $1 \mathrm{x}$ \\
\hline 20 & ausente & $5 a$ & recorrente \\
\hline 21 & $\begin{array}{l}\text { atenção, velocidade de } \\
\text { fala }\end{array}$ & $8 \mathrm{a}$ & recorrente \\
\hline 22 & ausente & $1 \mathrm{a} 2 \mathrm{~m}-2 \mathrm{a} 6 \mathrm{~m}$ & $3 x$ \\
\hline 23 & atenção, aprendizagem & $4 a-5 a$ & recorrente \\
\hline 24 & ausente & $1 a-3 a$ & recorrente \\
\hline
\end{tabular}

Legenda: a: anos $\mathbf{m}$ : meses 


\section{Anexo 6. Achados da observação clínica.}

Indivíduo 1: Na observação fonoaudiológica clínica observou-se adequação de todas as habilidades de linguagem, do ponto de vista receptivo e expressivo. A criança mostrou-se bastante comunicativa, expressiva, cativante e afetiva.

Indivíduo 2 - Na observação fonoaudiológica clínica encontrou-se normalidade na fonologia receptiva e expressiva e dificuldade nas demais habilidades da linguagem, apresentando uma fala bastante simples e comunicando-se muito pouco, sua elaboração era pobre. A criança não tinha os olhos vivos e brilhantes, apresentou dificuldades para compreensão verbal. Sua mãe não se mostrou estimuladora ou interessada nas orientações passadas.

Indivíduo 3 - Com a amostra obtida na observação fonoaudiológica clínica observou-se adequação das habilidades de linguagem expressivas. Na linguagem receptiva a criança mostrou dificuldade na compreensão de ordens complexas.

Indivíduo 4 - Na observação fonoaudiológica clínica a criança interagiu bem com a avaliadora, no entanto, foi difícil a avaliação, pois a criança cansou-se facilmente, chorou, fez manhas. Quanto às habilidades de linguagem oral apresentou fonologia adequada e dificuldades em semântica, sintaxe e pragmática, a recepção da linguagem também necessita ser estimulada; sua inteligibilidade de fala estava prejudicada pelos DACs.

Indivíduo 5 - Na observação fonoaudiológica clínica mostrou bom desempenho; a criança tem olhos brilhantes, comunicou-se muito bem, teve ótimo desempenho na linguagem expressiva em todas as habilidades, no entanto, na linguagem receptiva apresentou dificuldades. Apresentou trocas culturais do tipo ['praka] (placa) e ['grobu] (globo).

Indivíduo 6 - $\mathrm{Na}$ observação fonoaudiológica clínica a criança respondia às questões da avaliadora por meio de monossílabos, não iniciou ou manteve tópico conversacional, apresentou vocabulário reduzido, não fez uso de frases para se comunicar. Apresentou processos de 
simplificação na fala não mais esperados para sua idade: simplificação sistemática de consoante final $\{\mathrm{R}\}$, simplificação assistemática de encontro consonantal $(/ \mathrm{r} /)$ e distorção dos encontros consonantais $(/ \mathrm{r} /, / 1 /)$; mostrou dificuldade na linguagem receptiva. Apresentou trocas ortográficas e fonológicas na escrita.

Indivíduo 7 - Na observação fonoaudiológica clínica a criança mostrou-se quieta, tímida, falou pouco e muito baixo, houve dificuldade para interagir com a mesma. Apresentou normalidade na fonologia expressiva e dificuldade nas demais habilidades da linguagem, também verificou-se dificuldade na linguagem receptiva.

Indivíduo 8 - Na observação fonoaudiológica clínica percebeu-se que a criança é bastante manhosa, apresentou dificuldades para interagir. Apresentou vocabulário aquém do esperado e dificuldade na linguagem receptiva. A mãe é professora, muito estimuladora, interessada, questionou e solicitou informações detalhadas sobre como melhor estimular sua filha na linguagem oral e escrita. A criança apresentou trocas ortográficas e fonológicas na escrita.

Indivíduo 9 - Na observação fonoaudiológica clínica encontrou-se dificuldade somente em fonologia expressiva, as demais habilidades estavam adequadas, incluindo a linguagem receptiva. Os processos observados foram: ensurdecimento de plosiva $(/ \mathrm{d} /, / \mathrm{b} / . / \mathrm{g} /)$, ensurdecimento de fricativa $(/ \mathrm{v} /, / \mathrm{z} /, / \mathrm{J} /)$, sonorização de plosiva $(/ \mathrm{t} /)$. A criança apresentou trocas do tipo surda $\mathrm{x}$ sonora na escrita.

Indivíduo 10 - Durante a observação fonoaudiológica clínica a criança falou muito pouco, teve dificuldades em interagir. Manteve-se quieto, respondendo somente às questões da avaliadora, sem complementá-las ou expandi-las. Apresentou normalidade na fonologia expressiva e dificuldade nas demais habilidades da linguagem.

Indivíduo 11 - Na observação fonoaudiológica clínica a criança mostrou-se confusa, com dificuldade na linguagem receptiva, apresentou normalidade na fonologia, no entanto, as demais 
habilidades da linguagem estavam aquém do esperado para a faixa etária. A criança apresentou trocas ortográficas e fonológicas na escrita.

Indivíduo 12 - Na observação fonoaudiológica clínica observou-se que a criança apresentava olhos vivos, mostrou-se bastante comunicativa, expressiva, teve ótimo desempenho. Todas as habilidades da linguagem oral, tanto expressiva quanto receptiva, estavam dentro da normalidade. A criança apresentou trocas fonológicas na escrita.

Indivíduo 13 - Na observação fonoaudiológica clínica a criança mostrou linguagem aquém do esperado para sua faixa etária, necessitando de estimulação em todas as habilidades de linguagem, tanto expressiva quanto receptiva. Apresentou simplificação fonológica não esperada para sua idade (posteriorização de fricativa), vocabulário limitado, dificuldades em construção frasal, discurso pobre, compreensão verbal restrita. A criança apresentou trocas ortográficas e fonológicas na escrita, ensurdecimento de plosivas e fricativas na leitura.

Indivíduo 14 - Na observação fonoaudiológica clínica a criança interagiu com a avaliadora, relatou sua vida na fazenda com boa elaboração oral. A criança fez uso de simplificações fonológicas não esperadas (ensurdecimento de plosiva /g/, simplificação assistemática de encontros consonantais /r/ e /1/). Apresentou dificuldades em compreensão de ordens complexas.

Indivíduo 15 - Na observação fonoaudiológica clínica a criança mostrou excelente nível de comunicação, interagiu facilmente com a avaliadora, é bastante expressiva, faz uso de discurso bem elaborado, construções frasais adequadas, tem ótimo vocabulário, a criança referiu ler muito. Disse gastar sua mesada comprando livros novos, leitura é seu hobby. A criança mostrou-se alegre e interessada em todas as atividades propostas.

Indivíduo 16 - Na observação fonoaudiológica clínica a criança mostrou bom nível de linguagem, comunicando-se efetivamente, usando a linguagem adequadamente para sua faixa etária. Todas as habilidades de linguagem estavam dentro do esperado, do ponto de vista 
receptivo e expressivo.

Indivíduo 17 - Na observação fonoaudiológica clínica a criança interagiu com a avaliadora, comunicou-se muito bem, apresentou bom nível lingüístico, apresentando todas as habilidades de linguagem adequadas para a idade.

Indivíduo 18 - Na observação fonoaudiológica clínica a criança mostrou ter bom desempenho lingüístico, contou histórias com detalhes, com vocabulário rico, organização frasal adequada, habilidades de linguagem oral dentro do esperado para sua faixa etária, tanto do ponto de vista receptivo como expressivo.

Indivíduo 19 - Na observação fonoaudiológica clínica a criança conversou pouco, mostrou-se tímido, mas apresentou normalidade em todas as habilidades de linguagem; é esperto, inteligente, teve ótimo desempenho auditivo e visual, sendo melhor nas habilidades auditivas.

Indivíduo 20 - Na observação fonoaudiológica clínica a criança mostrou-se bastante inquieta e comunicou-se muito mal, teve desempenho lingüístico inferior ao esperado para sua idade. Apresentou dificuldade em nível receptivo e expressivo em todas as habilidades de linguagem. Evidenciaram-se simplificações fonológicas não esperadas para sua faixa etária (frontalização de nasal, simplificação assistemática de líquidas e de encontros consonantais). A mãe foi orientada. Indivíduo 21 - $\mathrm{Na}$ observação fonoaudiológica clínica a criança mostrou bom desempenho lingüístico, apresentando normalidade em todas as habilidades tanto receptivas quanto expressivas.

Indivíduo 22 - Na observação fonoaudiológica clínica a criança apresentou ótima interação e desempenho lingüístico, mostrou-se bastante comunicativa, com adequação em todas as habilidades da linguagem do ponto de vista receptivo e expressivo.

Indivíduo 23 - Na observação fonoaudiológica clínica a criança mostrou dificuldade de interação com a avaliadora. Não iniciou ou manteve diálogo. Mostrou vocabulário, construção 
frasal e fonologia dentro do esperado na amostra obtida, mas a habilidade conversacional estava prejudicada, a linguagem receptiva também mostrou-se defasada.

Indivíduo 24 - Na observação fonoaudiológica clínica a criança apresentou ótimos resultados, interagiu com a avaliadora, comunicou-se muito bem, apresentou bom nível lingüístico, apresentou adequação em todas as habilidades de linguagem. 